\title{
Bhutan - Macroeconomic and Public Finance Policy Note
}

\section{Hydropower impact and Public Finance Reforms towards Economic Self-Reliance}

\section{November 2015*}

Bhutan's hydropower generation potential raises the prospect of tremendous development opportunities for the country: fast increasing export revenue, sustained economic growth, and rapid poverty reduction. Driven by developments in the hydropower sector, the country has grown at an average rate of 7 percent per year over the last decade, while poverty has declined remarkably fast. But hydropower development also creates significant challenges:

- Macroeconomic instability. The massive scale of hydropower generation projects relative to the size of the Bhutanese economy generates large fluctuations in aggregate demand, both during the construction phase and when the projects are commissioned. Taken together, the three hydropower projects under construction have a cost amounting to 190 percent of the country's GDP. And hydropower exports already contribute 39 percent of government domestic revenues, a figure which is expected to increase to 56 percent by 2024/25. These inflows lead to an appreciation of the real exchange rate, foster inflation for non-tradable goods and services, and support real estate booms. As a result, the real interest rate is negative from the point of view of those involved in construction, leading to borrowing sprees and ultimately a shortage of foreign exchange (in the case of Bhutan, Indian's rupees) as happened in 2011.

- Lack of self-reliance. Today the Bhutanese government depends on donors to fund part of its budget and the country's current account deficit. Tax collection is low by international standard and has been on a declining trend relative to GDP. Against this background, higher revenues from hydropower are commonly seen as the solution to achieve the government's stated goal of fiscal self-reliance by 2020. However, this is a dangerous illusion. Revenue from hydropower exports will peak in a decade and then stabilize, whereas the public expenditures needed to expand the coverage and quality of social services will continue on an upward trend. Not factoring in this reversal of the fiscal selfsustainability gap could lead the authorities to be overly optimistic in hiring public sector workers and improving their pay and benefits.

* This note was prepared by Genevieve Boyreau (Resident Representative and Senior Economist for Bhutan) and Martin Rama (Chief Economist for South Asia), with inputs from Syed Rashed Al-Zayed Josh, Somneuk Davading, Tanvir Hossain, Achim Daniel Schmillen, Carlos Sobrado, Joel Turkewitz and Veronica Vargas. 
- Few private sector jobs. As a vibrant private sector has yet to emerge in Bhutan, the public sector is perceived as the preferred employer, including among educated youth who aspire to white-collar jobs. By now mostly every young Bhutanese lives in the hope of becoming a civil servant. But more hydropower developments will also mean real appreciation of the exchange rate through higher wages and land/real estate prices which will make it harder for the private sector to compete in export markets. Furthermore, because the hydropower revenues enter through the budget, the incentives to expand the size of the public sector are likely to rise, further crowding out the private sector.

Against this background, this note assesses the opportunities and challenges associated with hydropower development. It informs a possible strategy supportive of macroeconomic stability, fiscal self-reliance and private sector development. And it argues that fundamental changes in public finance, amounting to a paradigm shift, are central to the implementation of such strategy.

\section{The gains from hydropower development}

Bhutan is blessed with a massive potential for hydropower generation. Out of an estimated 30,000MW potential, 1,606MW are already operational and an additional 3,153MW are coming on line in 2018. Another 2,170 MW have reached agreement and are expected to start construction in 2015. Lastly, there is an additional 8,068 MW which has been identified in the longer-term pipeline. With energy-hungry India as its neighbor, the strategy of the government is to develop its hydropower resources to earn export revenues in surplus of domestic needs.

Generation projects have been implemented in partnership between the Government of Bhutan and the Government of India under three different development models:

- The Inter-Governmental (IG) model (67 percent of identified generation capacity): The Government of India is responsible for mobilizing the project's funding and implementing the project until the time of commissioning. The project ownership is then transferred to the Government of Bhutan, with a certain amount of debt repayment to the Government of India. The Government of India buys all the electricity generated in surplus of domestic consumption, at a price determined on a cost-plus basis, guaranteeing a net return of 15 percent to the Bhutanese government above debt repayment and the project's operating cost.

- The Joint-Venture (JV) model (14 percent of identified generation capacity): Projects are developed and commissioned under a Joint venture of Bhutan and India Public Sector Undertakings (PSUs) under a 50/50 percent ownership, with 70 percent being financed by loans raised by the PSUs, and 30 percent equity participation, out of which the Bhutanese share is financed out of grants provided by the Government of India. 
- The Public-Private Partnership (PPP) model (13 percent of identified generation capacity): So far, two PPP projects have been developed with the support of the Asian Development Bank (ADB) and the Government of Austria. ${ }^{1}$

For the purpose of the macroeconomic forecasts used in this policy note, we include in the projections all the projects commissioned, under construction, in the near pipeline and the Sankosh storage projects. Assumptions have been discussed and agreed with the respective members of the RGoB Macroeconomic Framework Coordination Technical Committee (MFCTC). The expected outcome is a steep increase in hydropower generation capacity, followed by stagnation (figure 1).

le 1: Hydropower projects in Bhutan

\begin{tabular}{|c|c|c|c|c|}
\hline Project name & $\begin{array}{l}\text { Cons } \\
\text { Date }\end{array}$ & $\begin{array}{l}\text { Com } \\
\text { Date }\end{array}$ & $\begin{array}{l}\text { Capacity } \\
\text { (MW) }\end{array}$ & $\begin{array}{c}\text { Development } \\
\text { model }\end{array}$ \\
\hline \multicolumn{5}{|l|}{ Commissioned } \\
\hline Tala & 1997 & 2007 & 1,020 & IG \\
\hline Chhukha & 1974 & 1988 & 336 & IG \\
\hline Dagachhu & 2009 & 2015 & 126 & PPP \\
\hline Basochu & 1997 & 2001 & 64 & Austrian Gov \\
\hline Kurichhu & 1995 & 2001 & 60 & IG \\
\hline \multicolumn{5}{|c|}{ Under Construction } \\
\hline Punatsangchhu I & 2008 & 2017 & 1,200 & IG \\
\hline Punatsangchhu II & 2011 & 2017 & 1,020 & IG \\
\hline Mangdichhu & 2011 & 2018 & 720 & IG \\
\hline Nikachu & 2015 & 2022 & 118 & PPP \\
\hline \multicolumn{5}{|c|}{ Near-Term Pipeline (agreed with India, April 2014) } \\
\hline Kholungchhu & 2015 & 2021 & 650 & JV \\
\hline Bunakha & 2015 & 2021 & 180 & JV \\
\hline Chamkharchhu & 2016 & 2025 & 770 & JV \\
\hline Wangchhu & 2016 & 2022 & 570 & JV \\
\hline \multicolumn{5}{|c|}{ Planned (Long Term Pipeline) } \\
\hline Sankosh Storage & 2017 & 2025 & 2,560 & IG \\
\hline Kuri-gongri & & & 2,800 & IG \\
\hline Rotpashong & & & 1,230 & PPP \\
\hline Amochhu storage & & & 540 & IG \\
\hline Nyera Amari & & & 473 & \\
\hline Khomachhu & & & 363 & PPP \\
\hline Gamrichhu & & & 102 & PPP \\
\hline
\end{tabular}

Source: Ministry of Economic Affairs, Department of Hydropower and Power Services

1 The equity of the Dagachhu project is distributed between DGPC (59 percent), Tata Power Company Limited of India (26 percent) and the National Pension and Provident Fund of Bhutan (15 percent), with the ADB, the Government of Austria and the NPPF providing loan funding. The Nikachhu project will be built and managed by Tangsibji (THyE), a special purpose company owned by the Bhutan Druk Green Power (public) Corporation. DGPC intends to sell $26 \%$ of THyE to a foreign private company in 2015. The funding comes from ADB, DGPC and a syndicated loan, from a consortium of Indian commercial banks. THyE has already signed a 25-year power purchase agreement with Power Trading Corporation of India, India's largest power trading company. 
The construction phase of these projects results in significant financial inflows into the economy. The inflows can reach as much a Nu50 billion, or the equivalent of a third of GDP (figure 2). Since these projects are highly capital intensive, most of the spending translate into imports (about 20 percent). Domestic spending, albeit smaller, is still high, picking up at Nu11 billion or 6 percent of GDP in 2016.

Figure 1: Hydropower generation capacity could triple over a decade

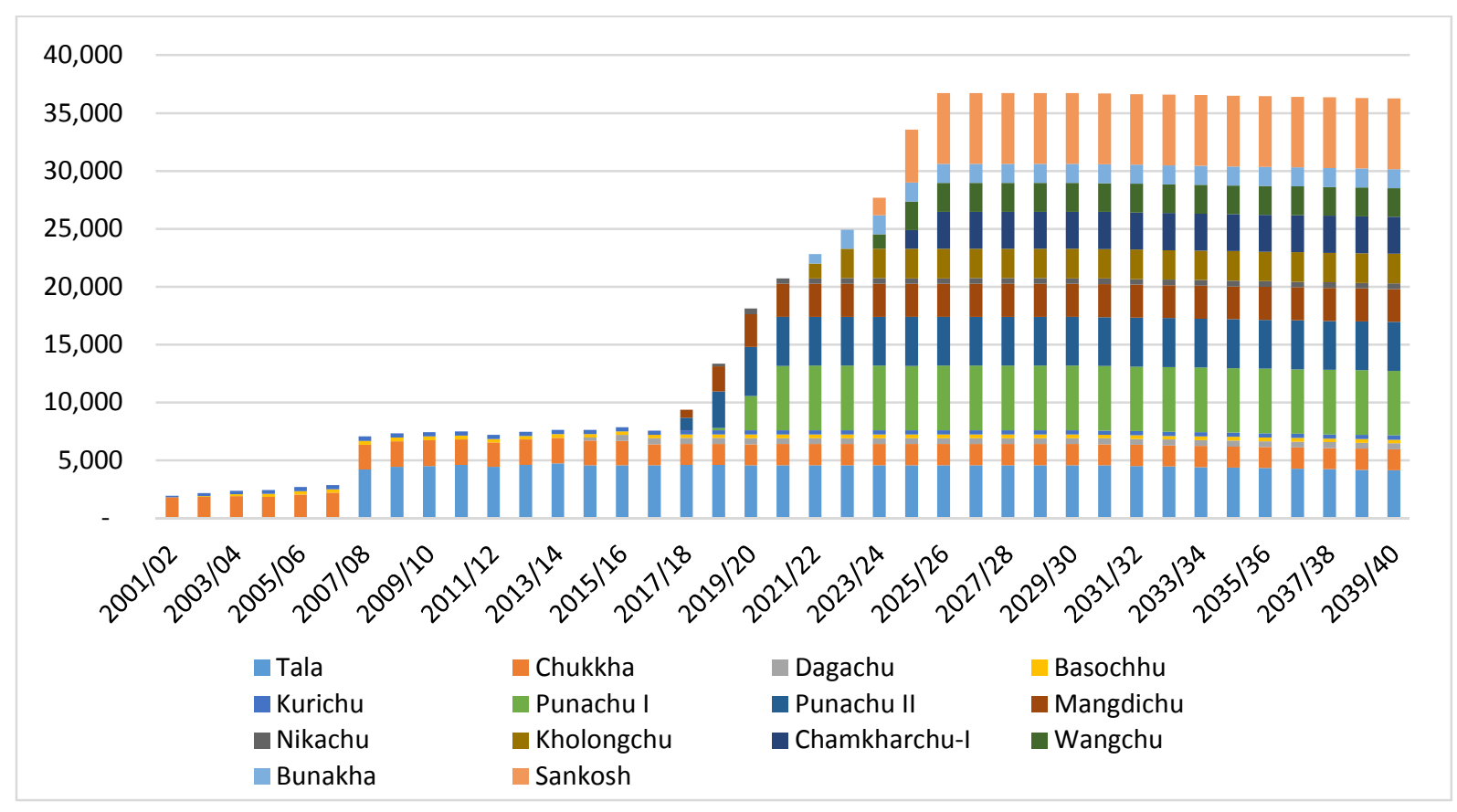

Note: Figures are in MW.

Source: RGoB Macroeconomic Framework Coordination Technical Committee and World Bank.

The development of hydropower generation capacity has a direct impact on several key macroeconomic indicators. The construction phase of the projects results in fast-growing external debt. The financial arrangement so far on IG projects had been that the cost of projects is financed by India with a combination of grants and loans (60 percent grant finance for commissioned projects and 30 percent for upcoming IG projects). ${ }^{2}$ The terms of the loans are usually 10 percent interest rate over a 10/12 year repayment period. Hydropower debt is directly serviced by Druk Green Power Corporation (DGPC - the Government holding of publicly owned hydropower projects) through the Ministry of Finance.

2 The share has turned to 30 percent grants and 70 percent loans for the recent IG projects. 
The growth of external debt is not necessarily a concern, as its service is largely self-financed by sales of electricity. Once hydropower projects shift to the generation phase, after commissioning, they result into significant export earnings. For example, Bhutan experienced a jump in export earnings at the time of Tala's commissioning in 2006 (Figure 2). Only electricity in surplus of domestic consumption is exported. But with domestic consumption of energy standing at about a quarter of total sales in 2014, Bhutan's headroom for electricity exports remains very comfortable over the foreseeable future. It is thus expected that the jump in export earnings will be even larger from 2017/18 onwards, with several projects starting selling electricity.

Figure 2: Revenue from electricity exports will surge even after subtracting debt service

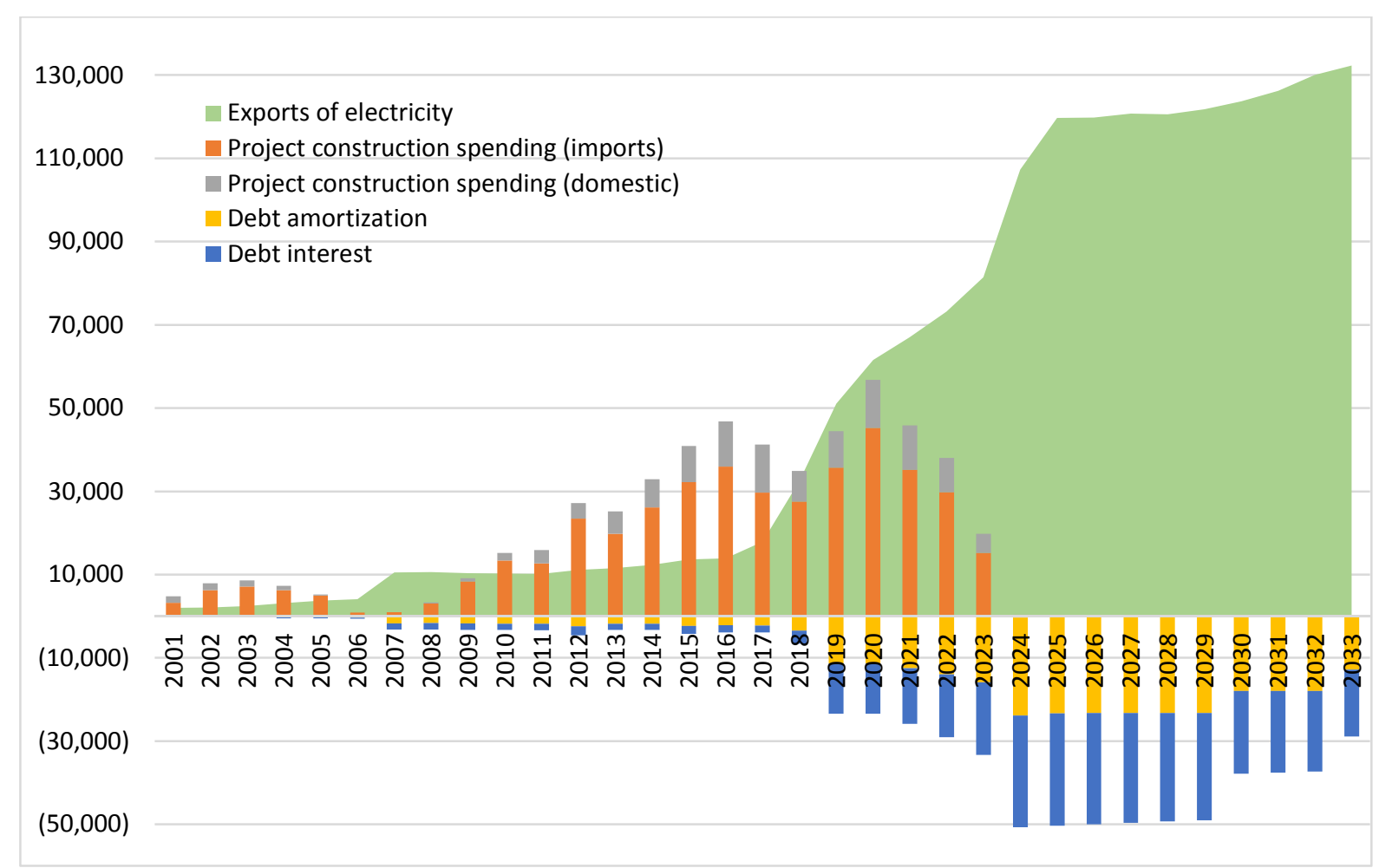

Note: Figures are in million Nu.

Source: RGoB MFCTC and World Bank.

The increase in export revenue from electricity will be large enough to finance the debt service associated with the construction phase of the hydropower generation projects. Albeit bulky, debt service represented 18 percent of hydropower export earnings in 2014, and is forecasted to reach a maximum of 38 percent of hydro exports over the next 30 years. The hydropower debt burden incurred under JV models will be shared between the Government of Bhutan and India along with their 50/50 percent share of ownership. 
Hydropower developments will continue to have a significant impact on economic growth in Bhutan. Their contribution comes from both the boost they give to aggregate demand during the construction phase of the projects, and the additional revenue they generate at the time of commissioning. From then onwards, their impact on GDP is mostly associated with adjustments to the price at which electricity is exported. The largest contribution of hydropower projects to economic growth so far was in 2007 (figure 3). But between 2013 and 2019, hydropower generation is expected to contribute one additional percentage point of economic growth every year. Taking into account the hydropower projects in the pipeline and under construction, GDP per capita is forecasted to reach US\$6,000 by 2030.

Figure 3: Hydropower development makes a strong contribution to economic growth

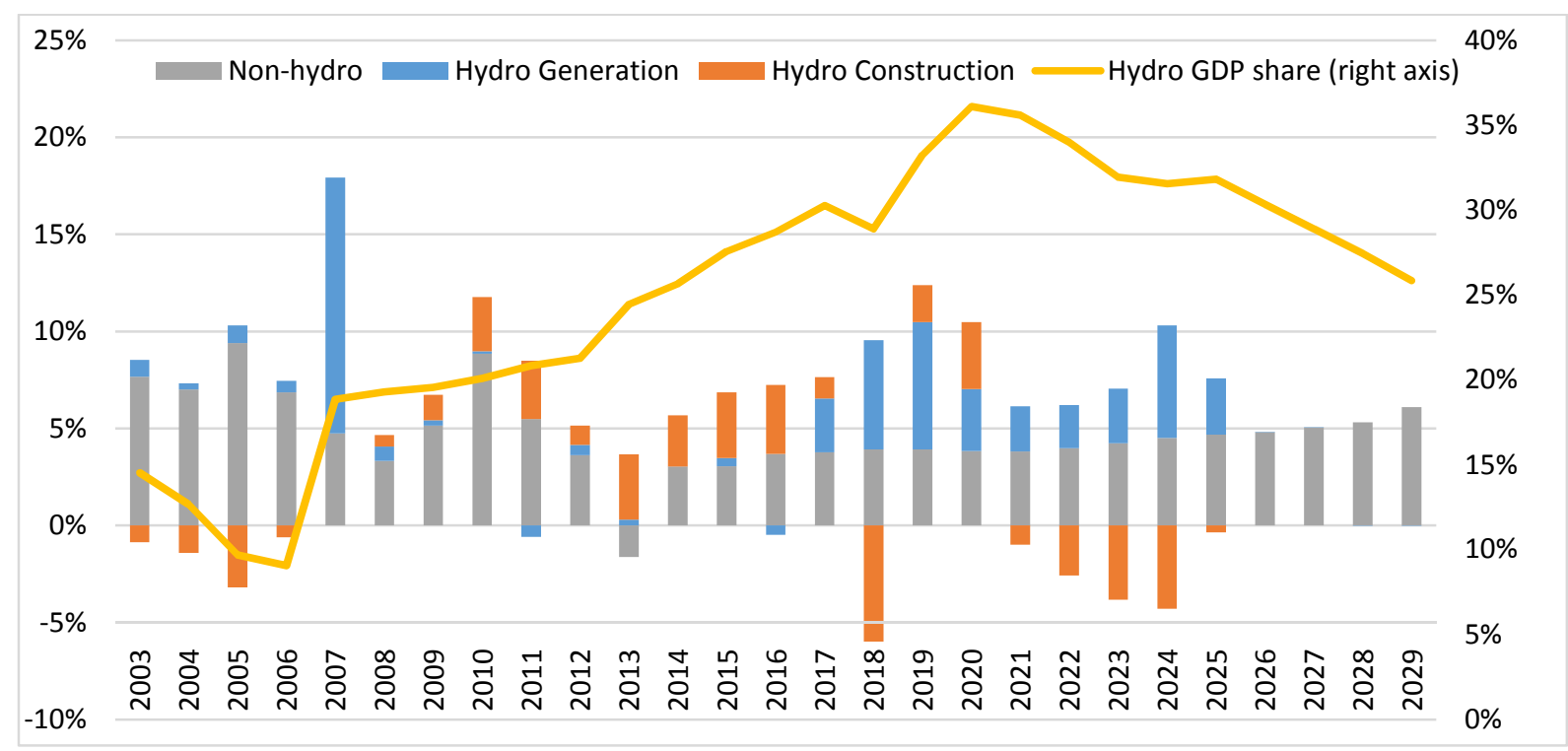

Source: RGoB MFCTC and World Bank Staff

Hydropower development will also continue to contribute to rapid poverty reduction. In addition to their impact on economic growth, hydropower generation projects boost demand for labor in rural areas which are among the poorest in the country. The local "spillover effects of hydroelectric projects serve also to boost local economies in the project site dzongkhags. During 2007-2012, work on four hydroelectric power projects was ongoing. The expenditure phasing of these project imply about $\mathrm{Nu} 13$ billion spent in the year 2012. Though most of the machinery and equipment are imported, construction work is expected to have significant local expenditures for transport services and for the foreign workers who live in Bhutan. As of 2012, there was one foreign worker for every eight Bhutanese counterparts. Hosting the living expenses of about 50,000 foreign workers (7 percent of population), valued at the poverty line, amounts to $\mathrm{Nu}$ one billion per year. This is a significant boost to the local economies of the dzongkhags. The estimated total consumption of the three dzongkhags was about $\mathrm{Nu}$ three billion in 2012, and the presence of 
foreign workers is estimated to augment spending by one-third. Some positive benefit to all the local suppliers, even at the lower end, can be expected - though this is hard to quantify." (World Bank, 2014).

\section{First challenge: macroeconomic instability}

The positive effects of hydropower development on Bhutan's economy - higher export revenue, manageable external debt service, faster economic growth, sustained poverty reduction - are undeniable. But hydropower development also raises important challenges, mainly arising from the bulky nature of the investments and the discontinuities associated with their commissioning. Bulkiness and discontinuity result in large macroeconomic fluctuations with disruptive effects, as illustrated by the "rupee crisis" of 2012-13. A development strategy based on the development of hydropower generation capacity needs to take this challenge into account.

Hydropower-driven growth results in large fluctuations in aggregate demand. The construction phase is associated with very large capital inflows. While these inflows are partially offset by imports of equipment and construction materials for the hydropower projects, they also translate into significant additional domestic demand, through direct domestic spending and indirect through spillover effects. Over the next couple of years, capital inflows will exceed 30 percent of GDP. Even after subtracting the associated imports, domestic demand will increase by up to 7 percent of GDP (figure 4).

Figure 4: Inflows to finance hydropower projects boost domestic demand

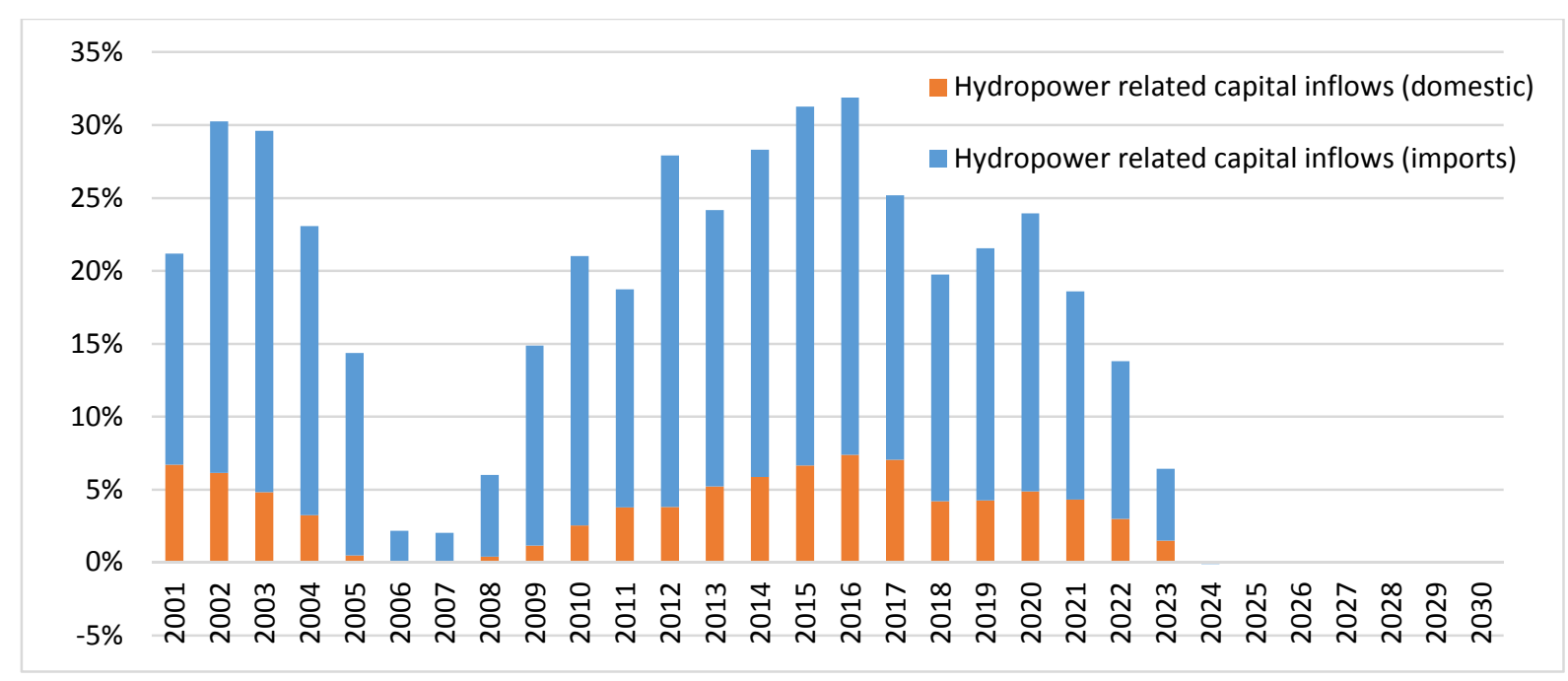

Note: Figures are in percent of GDP.

Source: RGoB MTFCTC and World Bank 
Some of the impact of hydropower development on aggregate demand takes place through the public sector. Once hydropower generation projects are commissioned they become Bhutanese public property and they income they generate boosts government revenue accounts. But hydropower projects also impact fiscal accounts during the construction phase, in a less visible way. Since hydropower investments are off-budget, they are not captured in the official fiscal stance. Assessing the true fiscal stance requires integrating hydropower investments into public spending as quasi-fiscal expenditures. Adding up quasi-fiscal spending from hydropower construction modifies the assessment of the government's fiscal stance (figure 5). While the difference between the official and the true fiscal stance was minor during the initial phase of hydropower development, during the current phase adding up-quasi fiscal spending increases public consumption by up to 6 percent of GDP, with a public sector deficit going up to 10 percent of GDP. Fiscal policy is thus much more expansionary than the official fiscal deficit suggests.

Figure 5: The true fiscal stance is highly expansionary during the construction phase

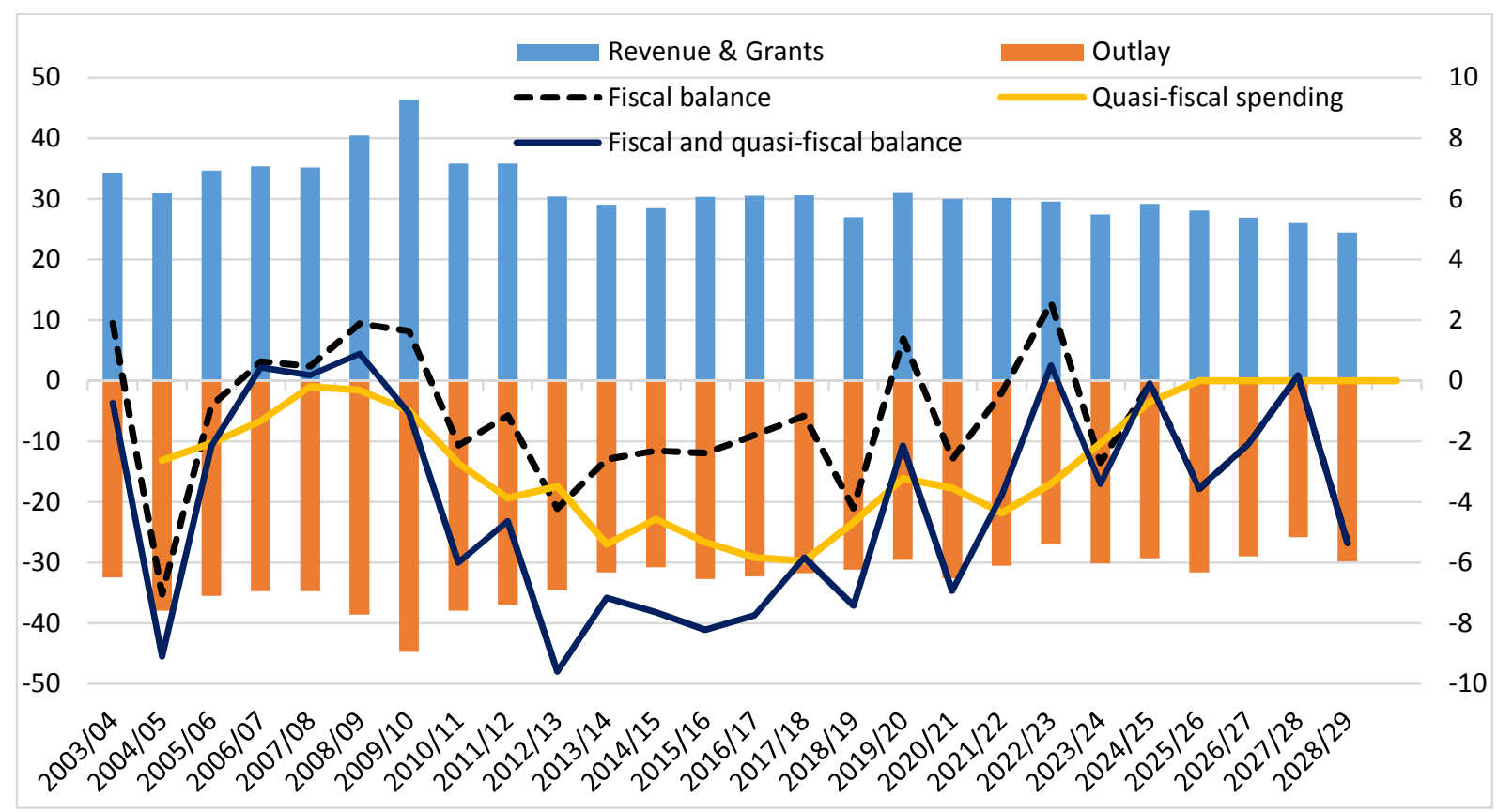

The combined effect of massive capital inflows and an expansionary fiscal stance is a large current account deficit. Electricity exports partially offset the hydropower-related deficit, especially from the end of the current decade onwards. But the boost to aggregate demand is so substantial that the non-hydropower related current account deficit is actually larger. Having started from a balanced current account in 2006/07, the deficit is expected to attain a third of the country's GDP by $2017 / 18$ (figure 6).

Financing the current account deficit is not as big a concern as handling the impact of its fluctuations on aggregate demand. Put differently, the external imbalance is very visible, but a 
much bigger challenge comes from the associated - but much less obvious - internal imbalance. Between 2009/10 and 2011/12 the current account deficit increased by the equivalent of 20 percent of GDP. Over the next four years, it could expand by 10 percent of GDP. Finance by the Government of India and by foreign investors can provide the resources to afford it. But the impact on the domestic economy is more difficult to handle.

Figure 6: The current account deficit surges during the hydropower construction phase

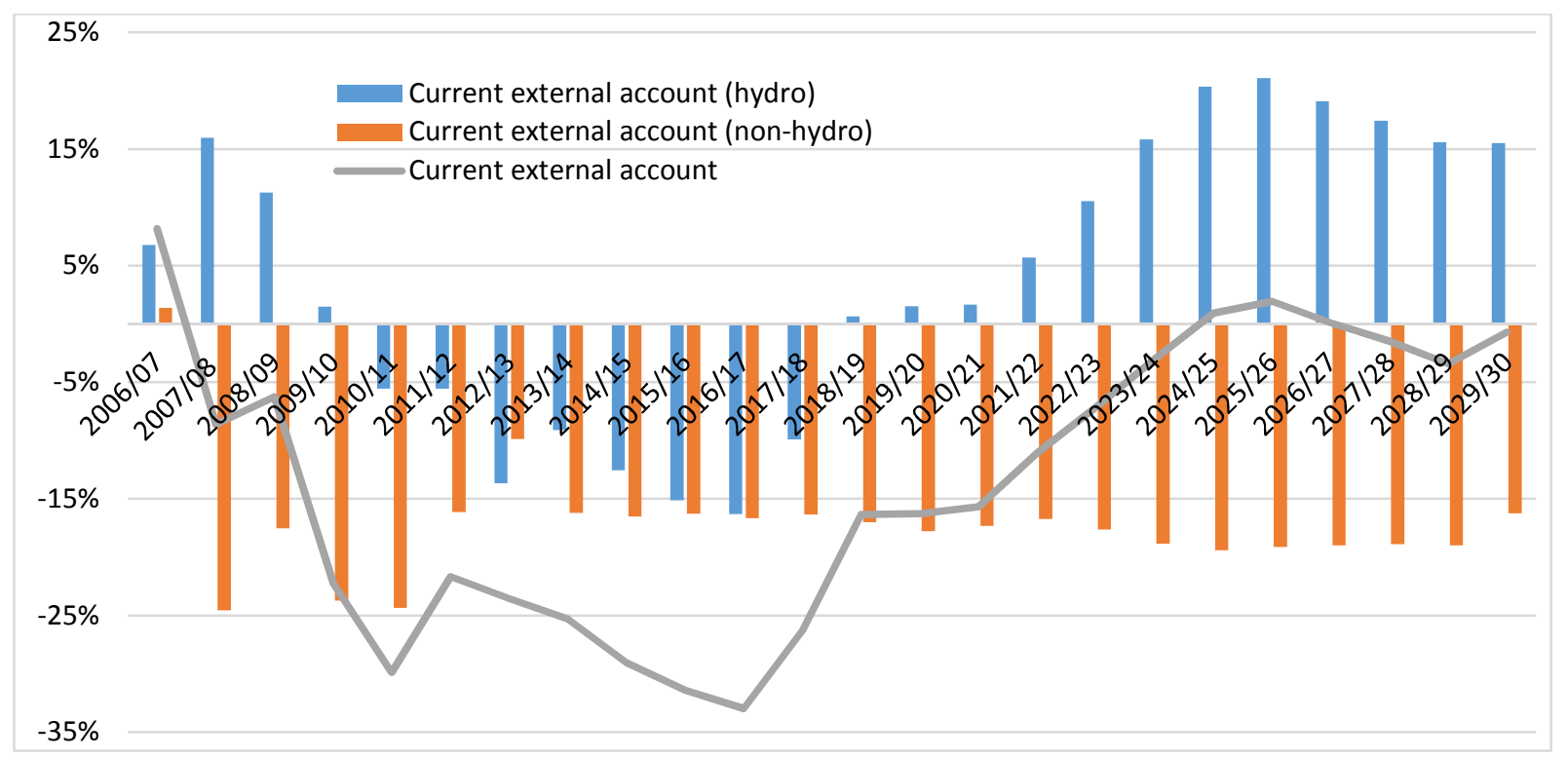

Note: All figures are in percent of GDP.

Source: RGoB MFCTC and World Bank.

Surges in the current account deficit take place through dramatic changes in relative prices. For imports to grow so much more rapidly than exports, domestic prices (and costs) need to become expensive relative to international prices. In practice, the additional aggregate demand from the expansionary fiscal stance and the large capital inflows boost the domestic prices of labor and housing (figure 7). With a fixed exchange rate, the prices of goods that can be imported cannot increase substantially. But labor and land are non-tradable, and as they become more expensive they reduce the competitiveness of all activities using them as inputs.

This change in relative prices also affects financial sector stability. With housing prices increasing much faster than inflation, it becomes profitable to borrow to buy or build housing. If the surge in the price of non-tradable goods is large enough, the nominal interest rate becomes lower than the increase in the price of housing. Or, put differently, the real interest rate as seen from the borrower's perspective becomes negative. Under these circumstances there is a large increase in the demand for credit. This is how the surge in the current account deficit between 2009/10 and 2011/12 led to the rupee crisis. Between the first quarter of 2010 and the first quarter of 2011, 
housing price inflation was higher than the interest rate. As the deficit stabilized during the last year or so, the rupee shortage eased too, but the relief could be temporary only, given that over the next four years the deficit could increase by another 10 percent of GDP. For this to happen, the prices of non-tradable goods will need to increase rapidly once again, leading to a new construction boom and to renewed demand for banking credit, and rupees.

Figure 7: Rapid increases in housing prices make it profitable to borrow for real estate

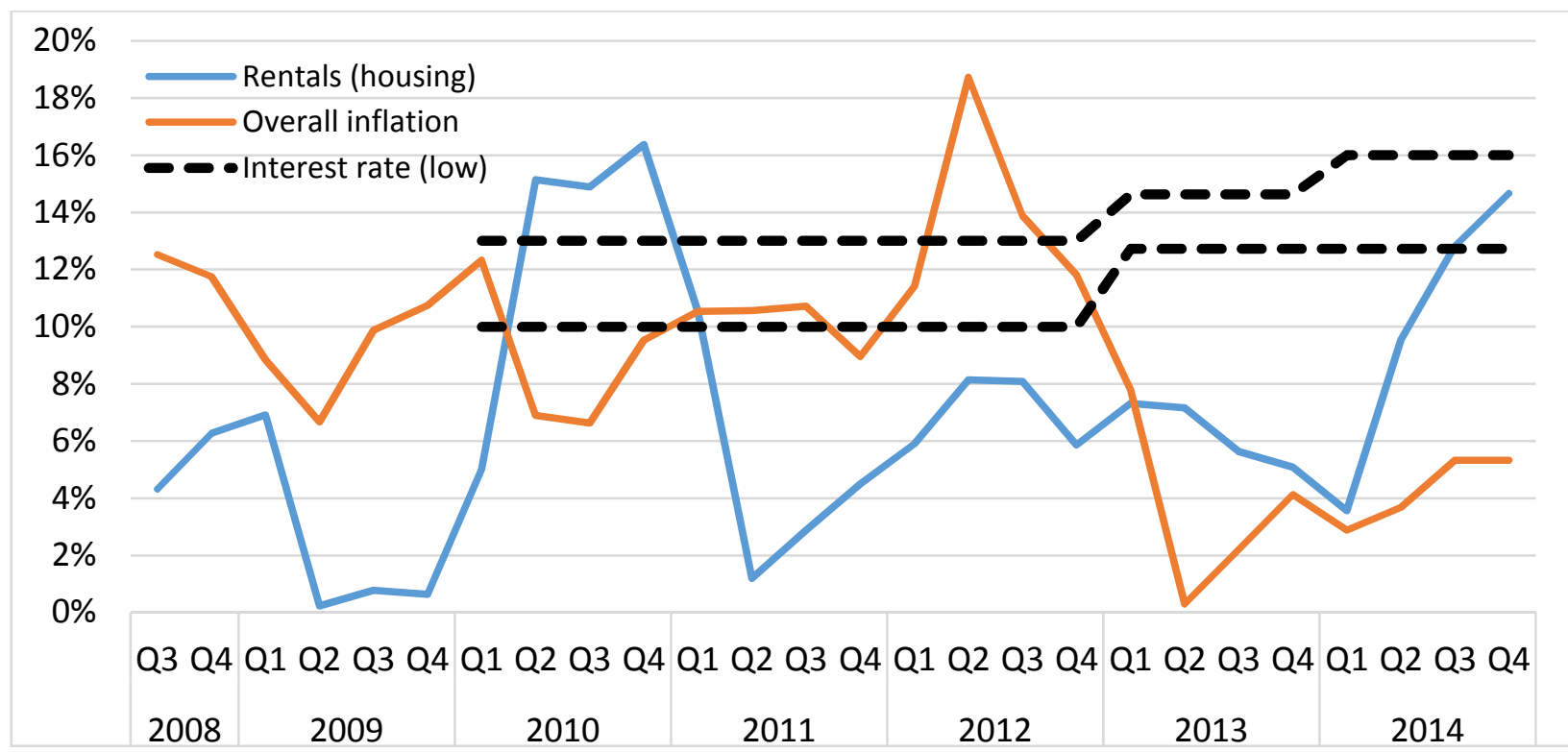

Source: National Statistics Bureau and Royal Monetary Authority

\section{Second challenge: lack of fiscal self-reliance}

Only a fraction of public investment in Bhutan is currently funded out of domestic tax revenue. For hydropower generation projects, which qualify as quasi-fiscal public expenditures, most of the financing is from abroad. For other public investments, Bhutan's still relatively low income per capita makes it eligible for grants and concessional finance from multilateral and bilateral donors. The share of public investment not covered by government revenue is known as the gap in fiscal self-reliance. As revenue from electricity exports increases this gap will decline and it could vanish by the next decade (figure 8). However, this relief is illusory. As no new hydropower revenues come on line after 2027/28, while the economy keeps growing, the gap in fiscal self-reliance will start increasing again until converging to its current level of about 15 percent of GDP.

For Bhutan to secure fiscal self-reliance it will need a determined effort to contain the growth of its public expenditures, and to increase its government revenue. Changes of this sort do not happen overnight, which is why initiating the necessary reforms now is critically important. The expected 
increase in revenue from electricity exports may create the impression that the gap in fiscal selfreliance is taking care of itself. But this is a dangerous illusion. Tax revenue is declining relative to the country's GDP, recurrent expenditures could surge in the medium term, and actual capital expenditures do not always match government plans. In the absence of a clear long-term plan and determined action, Bhutan could be forced to scale down its public investment program, hence to move more slowly towards attaining its development goals.

Figure 8: Electricity exports will reduce the gap in fiscal self-reliance but only temporarily

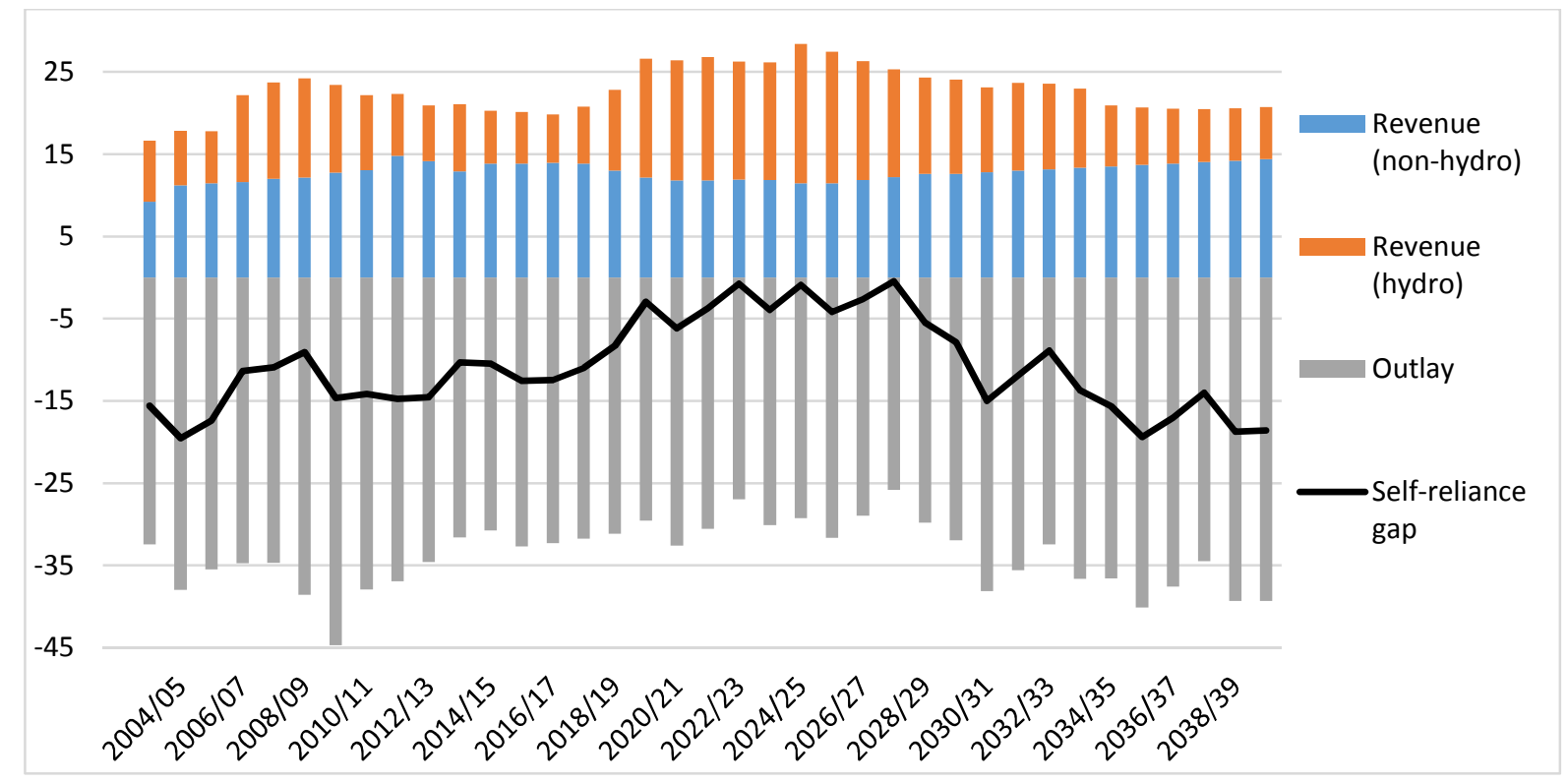

Note: All figures are in percent of GDP.

Source: RGoB Macroeconomic Framework Coordination Technical Committee and World Bank

The decline in tax revenue - relative to GDP - in recent years is not due to a change in tax instruments or in tax rates, but rather to policy decisions freeing specific groups of tax payers from their obligations, totally or partially. Tax holidays and exemptions from Business Income Tax are increasingly common. Similar loopholes can be found in the case of indirect taxes - Sales Tax, Custom Duties and Excises (table 2). There are 11 rate brackets for the Sales Tax, ranging from 0 to 100 percent, which reduces transparency and makes administration burdensome. Sales Tax exemptions result in 50 percent of foregone revenue. And around 63 percent of all imported commodities, accounting for 37 percent of all import value, are exempted from Custom Duties.

This complex set of exemptions and special regimes results is an implicit tax rate on household income that is low across most population groups. The overall Property, Vehicle and Income tax rate is high for households with higher consumption levels. But when combining it with Personal Income Tax, there is little difference in the total tax rate paid by many households with different 
consumption levels. ${ }^{3}$ For example, the poorest half of the population pays the equivalent of about 0.5 percent of its consumption in direct taxes, and the next third pays about 1.5 percent (figure 9 ). On the positive side, four out of five people live in households paying taxes, which is quite exceptional for a country at Bhutan's development level. But the low implicit rate implies that overall government revenue from direct taxes is modest. And it will decline further if the threshold for paying Personal Income Tax is lowered.

Table 2: Much revenue from indirect taxes is foregone due to exemptions

\begin{tabular}{|l|r|r|r|}
\hline & 2011-2012 & \multicolumn{1}{|c|}{$2012-2013$} & \multicolumn{1}{|c|}{$2013-2014$} \\
\hline Taxes foregone (Nu million) & 3,027 & 2,456 & 2,318 \\
As a share of total taxes & $21 \%$ & $16 \%$ & $15 \%$ \\
as a share of GDP & $3.3 \%$ & $2.3 \%$ & $1.9 \%$ \\
\hline
\end{tabular}

Source: Data provided by the Royal Government of Bhutan and World Bank staff.

Figure 9: Direct taxes only account for a marginal fraction of household expenditures

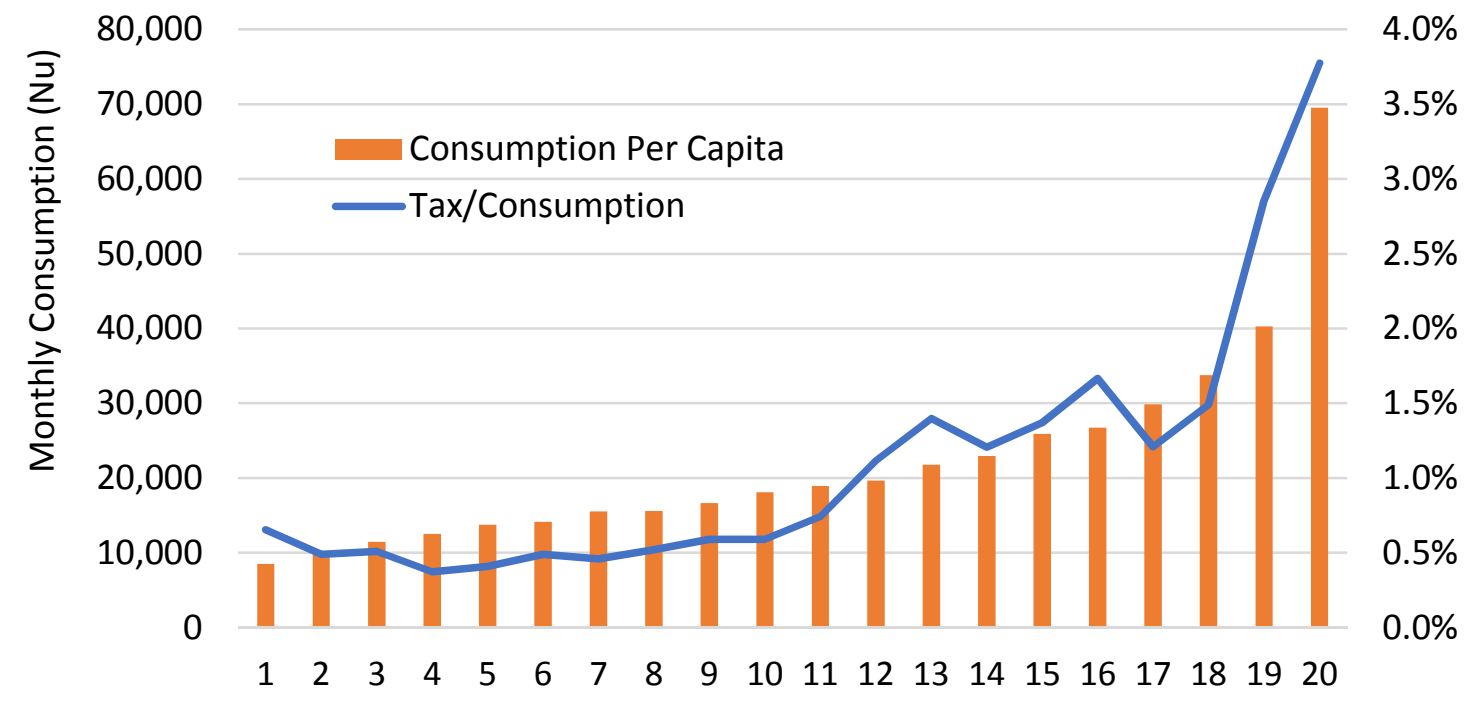

Consumption groups with same population (from poorest to richest)

Note: Value for group 15 is an average of groups 13.14.15 and 17 (reported value was inconsistent) Source: World Bank staff estimates based on BLSS 2012 Household survey.

3 Due to data limitations, consumption is used as a proxy for income. 
Tax holidays and exemptions not only reduce revenue: they also distort incentives and undermine the overall fairness of the tax system. On the incentives side, the after-tax return on investment across sectors drifts away from actual return, whereas formal employment is discouraged because it is more susceptible to taxation than (informal) self-employment. This is especially unfortunate for a country where both capital and good jobs are still scarce. On the fairness side, the implicit tax rate on households depends on their source of income. For the same income level, farmers, low-wage earners and owners of capital are less taxed than owners of small businesses and highwage earners.

As for public expenditures, the pressures to expand them in the coming years will mainly come from the social sectors. The growing revenue base from hydropower exports combined with the aspirations of an emerging middle class and the needs from an ageing population make this trend almost unavoidable. Providing secondary - and even tertiary - education to children and youth, while coping with the growing importance of non-communicable diseases among adults will require more public spending on education and on health.

Figure 10: The Education Blueprint will lead to a large increase in public spending

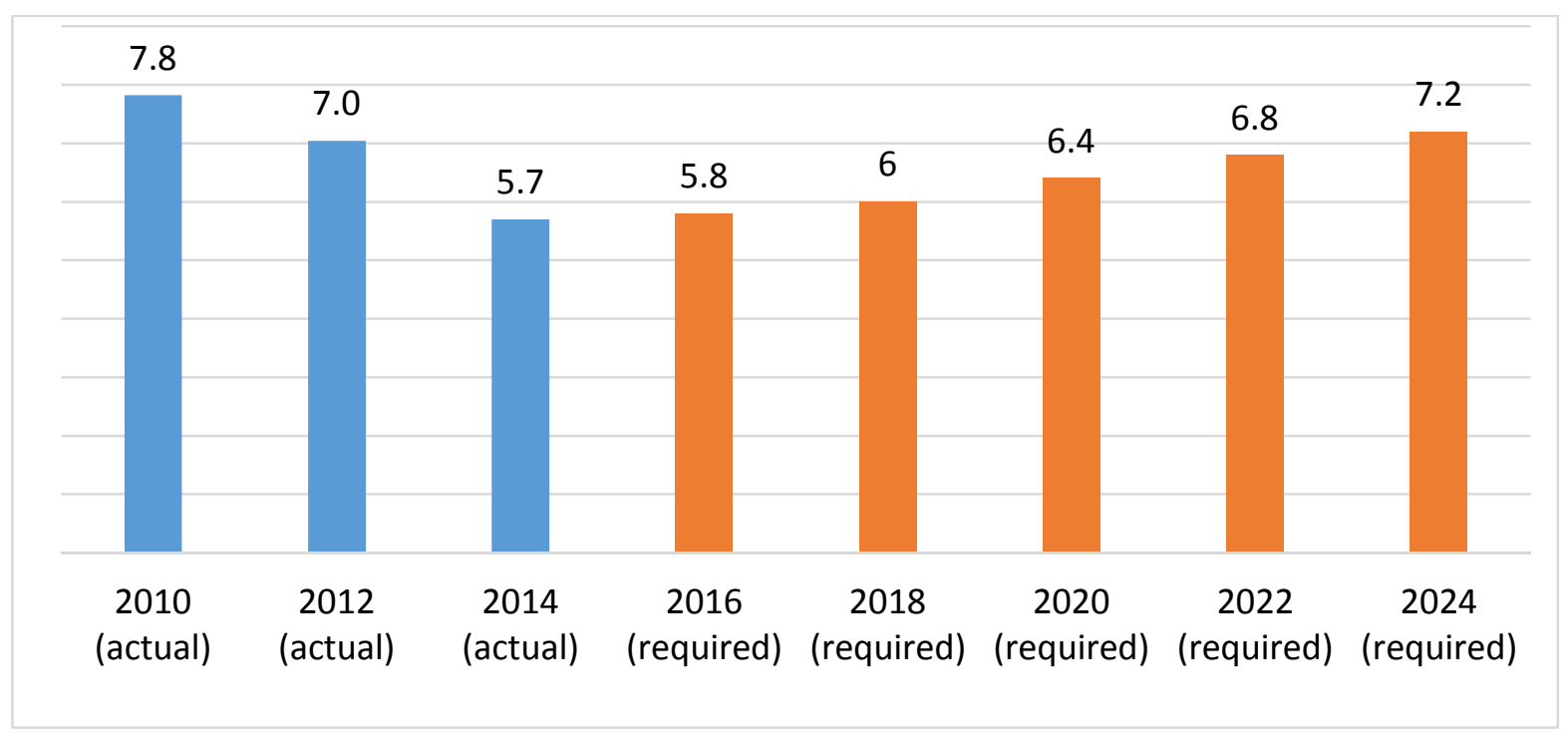

Source: Ministry of Education and World Bank projections

The Education Blueprint recently submitted to the Parliament illustrates this point (figure 10). Under the current growth trajectory, the budget envelope allocated to the education sector will need to rise from the current 5.7 percent to 7.2 percent of GDP by 2024, to adequately support the outlined policy priorities towards 2024. These include universal coverage of basic and higher secondary education (PP-XII), 80 percent adult literacy, enhancing quality across subsectors, 
significantly boosting access in ECCD from 10 percent to 50 percent, and expanding the coverage of special education, from the current level of 0.2 percent to 1.4 percent. The introduction of the central schools system will add significantly to future public expenditures, as the target is to have 50 percent of students in boarding schools by 2024 (compared to 24 percent in 2014), and boarding increases the cost per student by 30 percent. In relative terms, spending on tertiary education and technical and vocational education is bound to increase even faster (figure 11).

Figure 11: Enrollment in tertiary and in technical and vocational education will surge

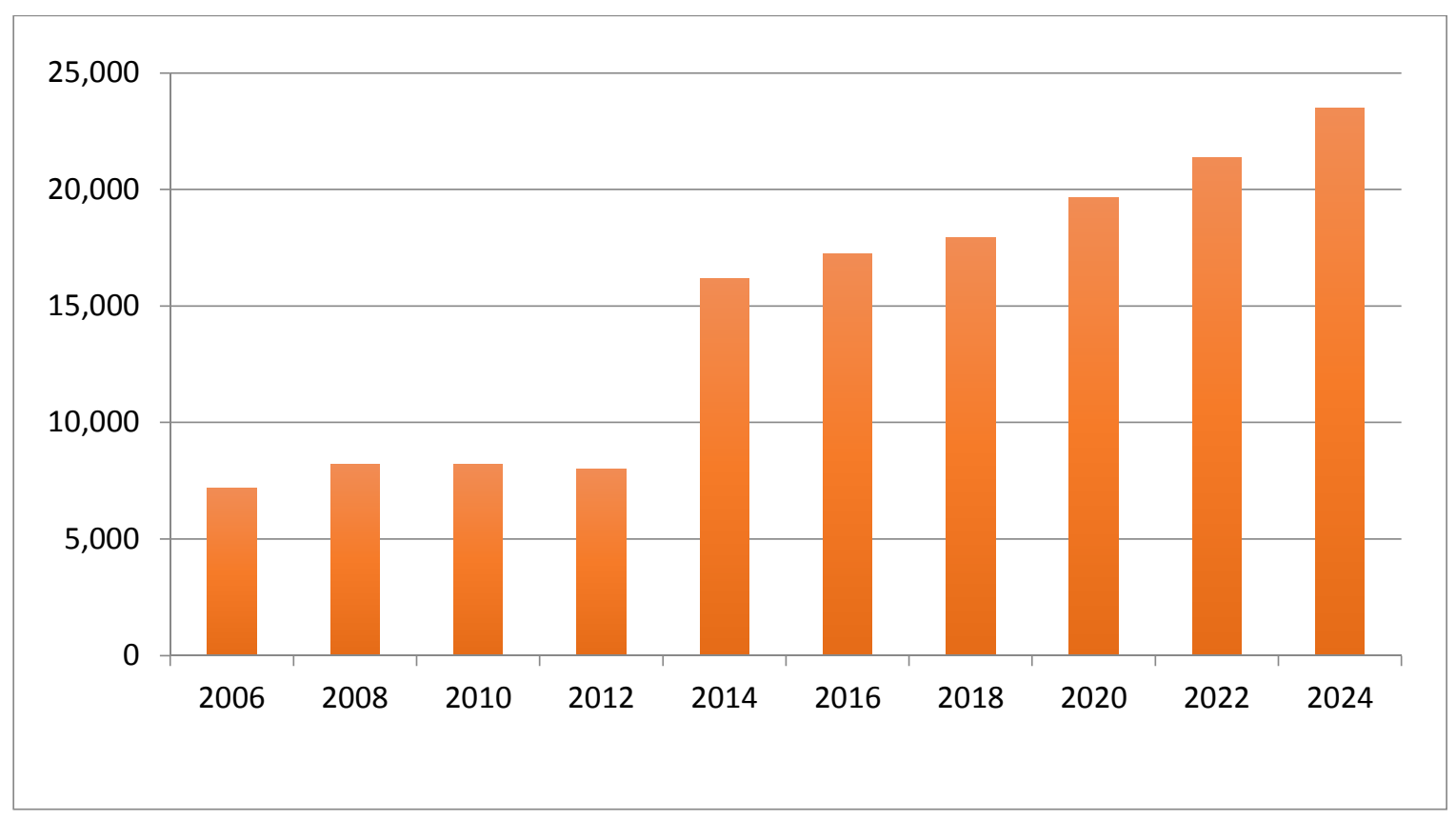

Source: Ministry of Education and World Bank staff estimates

Health spending is also expected to steadily increase. Bhutan is going through a demographic and epidemiological transition, shifting from communicable diseases to a dual burden of communicable and non-communicable diseases. Through the reduction of communicable and childhood diseases, Bhutan has increased life expectancy at birth from 59 years in 1990 to 69.5 years in 2010. But longer lives are associated with more years of ill health and a higher prevalence of chronic diseases (figure 12). Cancer is one of them, with the number of related deaths expected to reach 392 in 2020, an increase of more than 70 percent in just one decade. The cost of treating non-communicable diseases such as cancer, ischemic heart disease and cardiovascular diseases is particularly high. It is projected, for example, that the total expenditures for treating cancer patients will double in this decade (2010-2020). Bhutan can thus expect to see its public expenditure on health ballooning in the coming years.

A separate challenge to fiscal self-reliance, in addition to declining tax revenue and rapidly raising public expenditures, is the growing disconnect between planned and actual spending. This 
disconnect undermines accountability and opens the gate to opportunistic pressures on government spending. Disconnect reflects the compounded effect of gaps between the plan and the budget, and gaps between budgeted and actual expenditures (figure 13).

Figure 12: Non-communicable diseases are becoming more prevalent

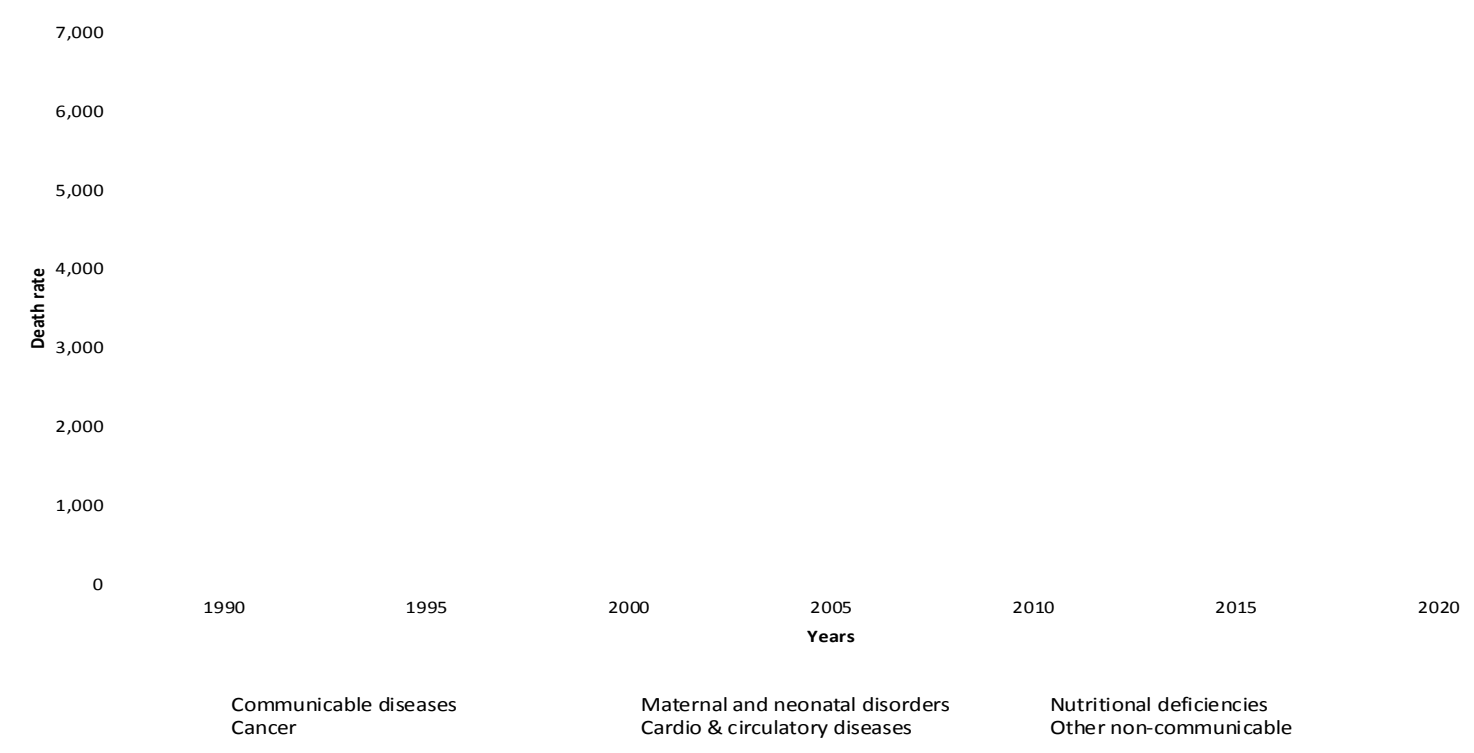

Source: Institute for Health Metrics and Evaluation, GBD Database, Seattle, WA: IHME, University of Washington, and staff projections.

Figure 13: Gaps between planned and actual capital expenditures are sizeable

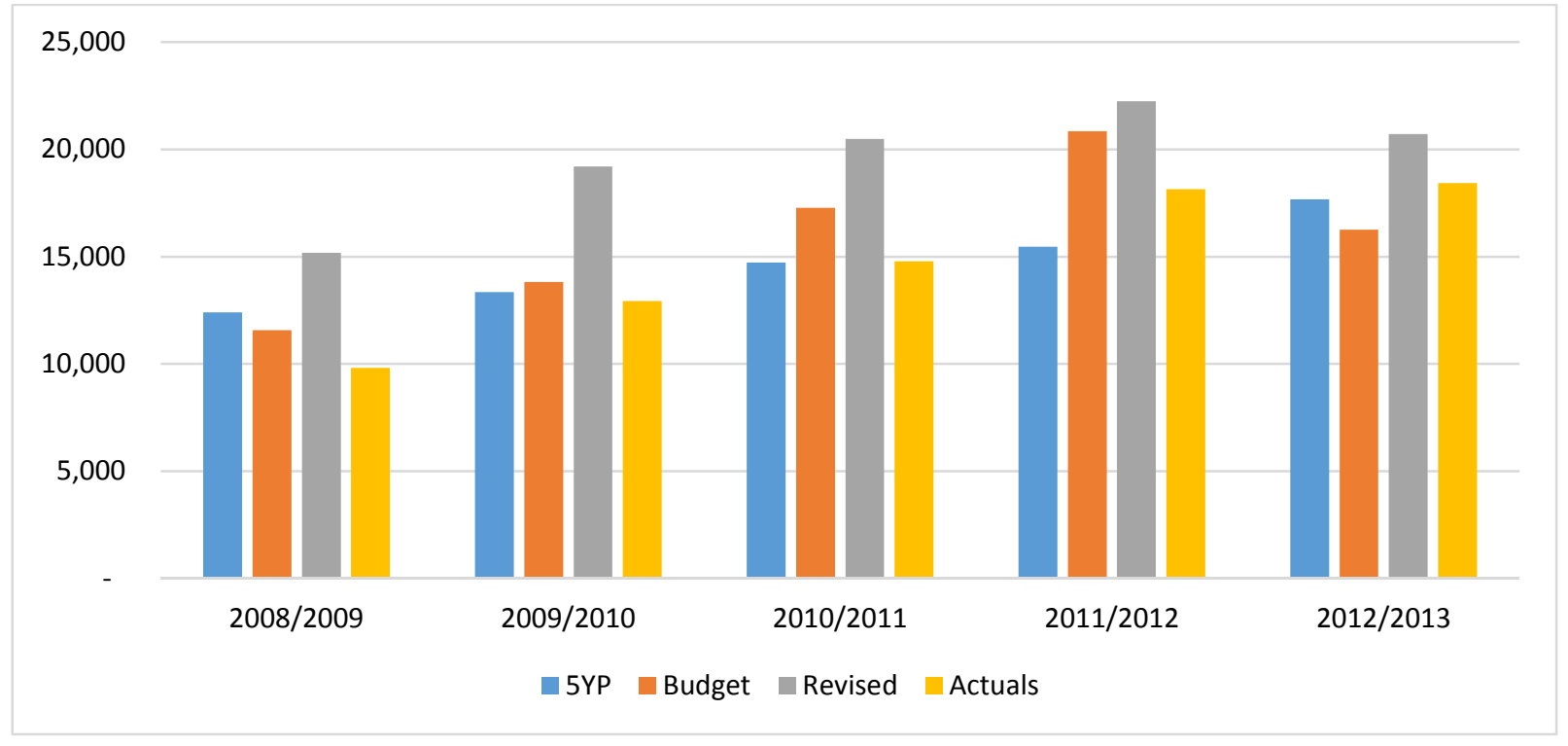

Note: Figures are in million Nu.

Source: 10th five year plan and government financial statements 
Bhutan currently combines five-year plans with a medium-term fiscal framework and annual budgets. The planning approach was more relevant when a major share of government income came from donor grants. As the extent of self-reliance increased over time, the five-year plan gradually became a set of targets for key development outcomes, with an associated list of eligible public investment projects and strong public investment planning mechanism. The link between the five-year plan and the budget was further weakened by the mismatch between the planning cycle and the election cycle. Because both the five-year plan and the sector strategies entail often more spending than can be afforded, public investment projects and sector programs end up being selected based on the resources available each year, which may not be the best way to prioritize.

\section{Third challenge: few private sector jobs}

Bhutan seeks to diversify its exports beyond electricity, and the development of a vibrant private sector is key to the success of this agenda. The government has been actively taking measures to improve connectivity, strengthen the investment climate and attract investors, in the hope of fostering job creation by the private sector. Youth are increasingly educated, opening the prospect of greater competitiveness in skill-intensive sectors. And yet available jobs remain vacant, while many of those educated youth queue for public sector jobs. When asked about their preference, a majority of unemployed persons in Bhutan respond that they want to work in the public sector (Figure 14).

Figure 14: Most of the unemployed want to work in the public sector

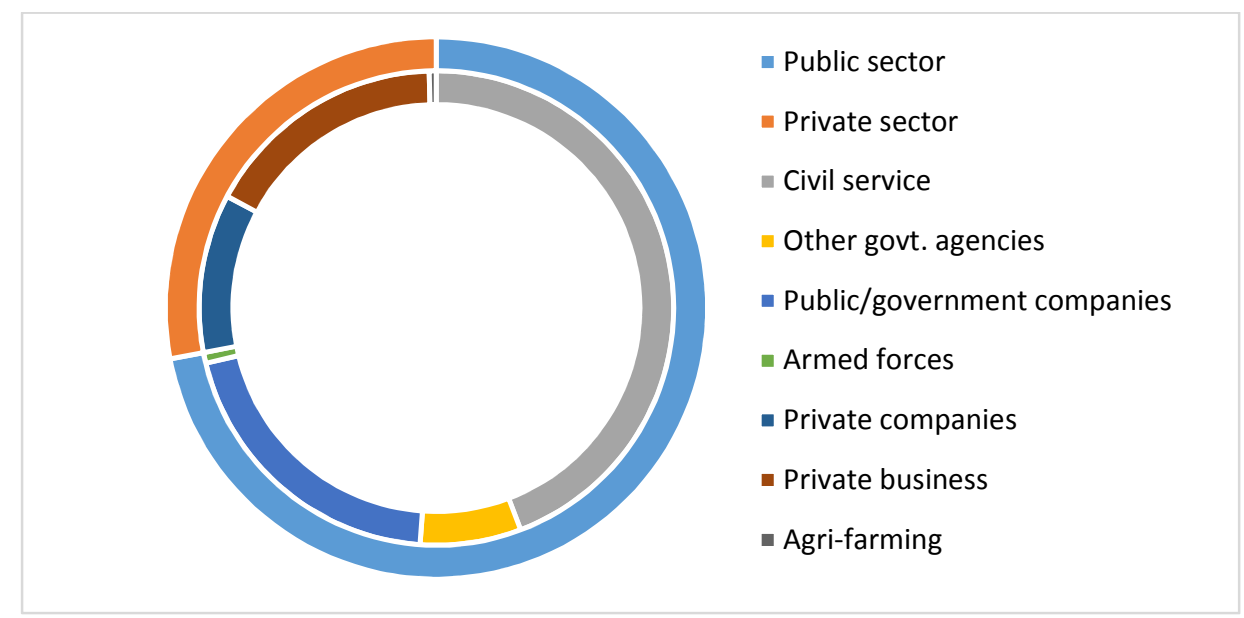

Note: Based on responses by 407 unemployed persons, number are not weighted.

Source: Bhutan Labor Force Survey 2014. 
Bhutan's public sector already accounts for a substantial fraction of total employment. The government sector, defined as the civil service, other government agencies and the armed forces (but not government-owned companies) provides 15.2 percent of all jobs. This figure is relatively high in international perspective, especially when comparing to other countries with a similar level of GDP per capita (Figure 15). If the government were to address queuing by expanding public sector employment further, the private sector would increasingly be crowded out, shrinking the country's tax base and making it more difficult to attain fiscal self-reliance.

Figure 15: Government employment in Bhutan is already large in international perspective

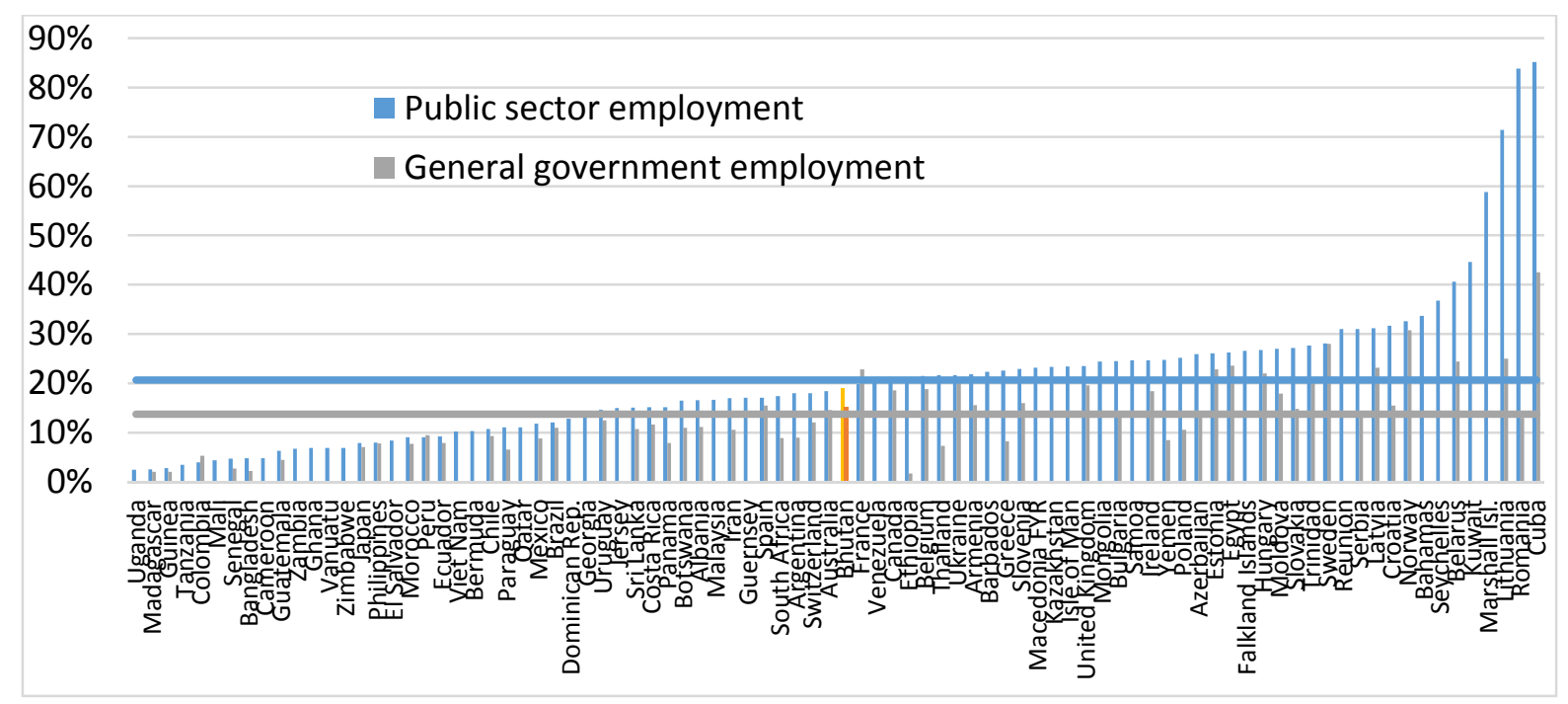

Source: World Bank staff estimates based on BLFS 2014, ILOSTAT database and Statistical Annex of the World Development Report 2013.

Jobs differ along a range of characteristics, including their pay, the benefits they provide, the degree of job security, the effort level required, and their social status. A job with relatively low pay may still be preferred to a better-paying job if its non-monetary dimensions are better. Typically, public sector jobs offer benefits such as old-age pension which are not available to farmers and the self-employed, and only to a fraction of wage earners in the private sector. Job security tends to be higher in the public sector than in the private sector, and effort levels tend to be lower. In many developing countries, public sector jobs are also considered more prestigious. If, on top of all these non-monetary advantages, public sector jobs pay higher salaries, then it is perfectly rational to queue for then.

To determine whether public sector pay is above labor earnings in the private sector, it is necessary to take into account the differences in the characteristics of workers in the two sectors. At the same time, private sector jobs and private sector workers are different than public sector jobs and public sector workers across the earnings distribution (figure 16). For instance, in the bottom half of the 
earnings distribution 72 percent of private sector workers have not completed any formal education whereas this is the case for only 41 percent of public sector workers. In the top half of the distribution, 13 percent of private sector workers but 36 percent of public sector workers have completed tertiary education. Similarly, in the bottom half of the earnings distribution 16 percent of private sector jobs are filled by regular paid employees whereas the corresponding figure for public sector jobs is 92 percent. In the top half of the wage distribution, 19 percent of private sector jobs and 96 percent of public sector jobs are filled with regular paid employees. This suggests that at least a part of the pay gap between public and private sector jobs might be explained by observable differences between private and public sector workers and jobs, with the contribution of such observable characteristics varying over the earnings distribution.

Figure 16: The characteristics of public and private sector jobs are different
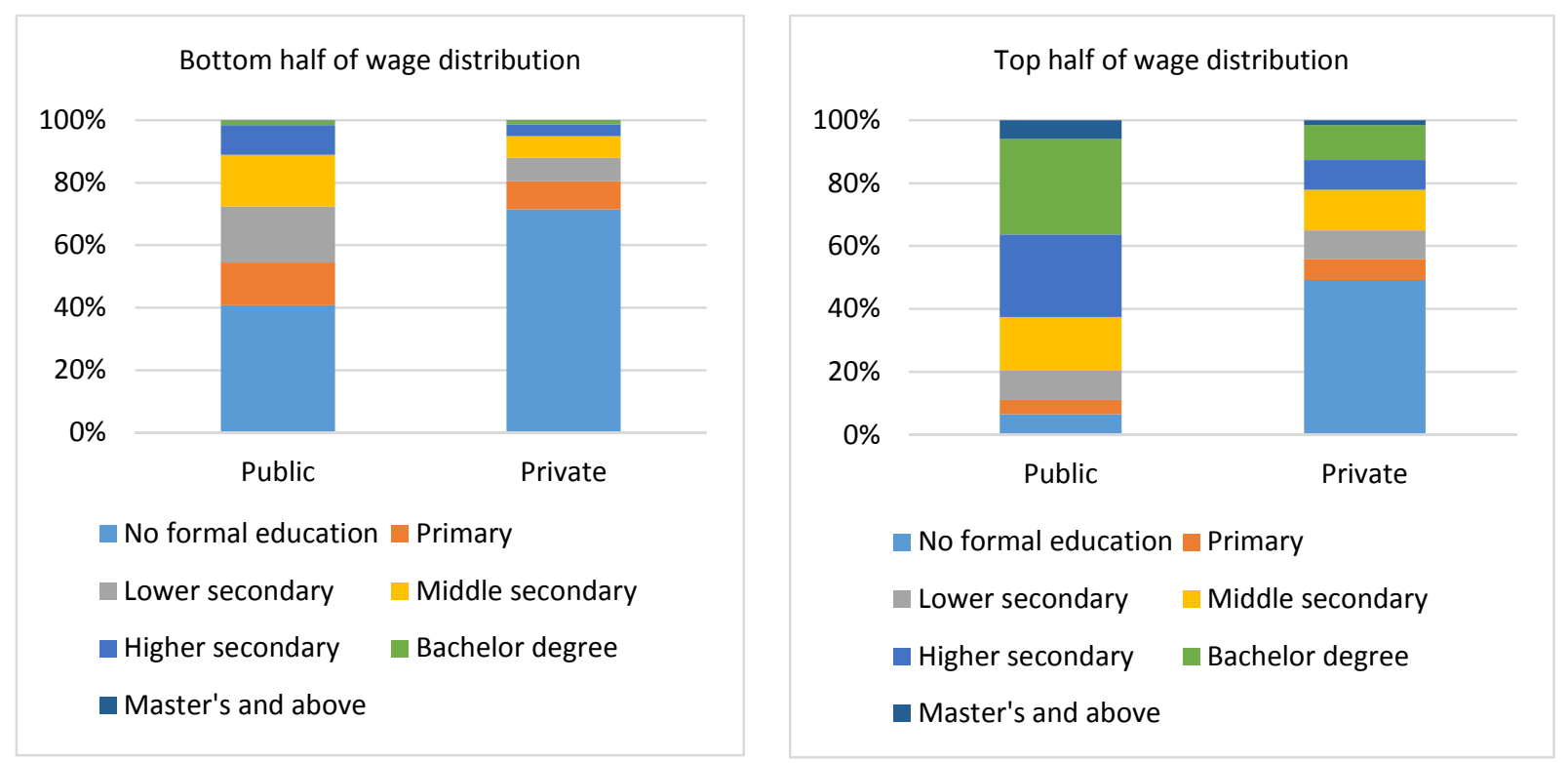

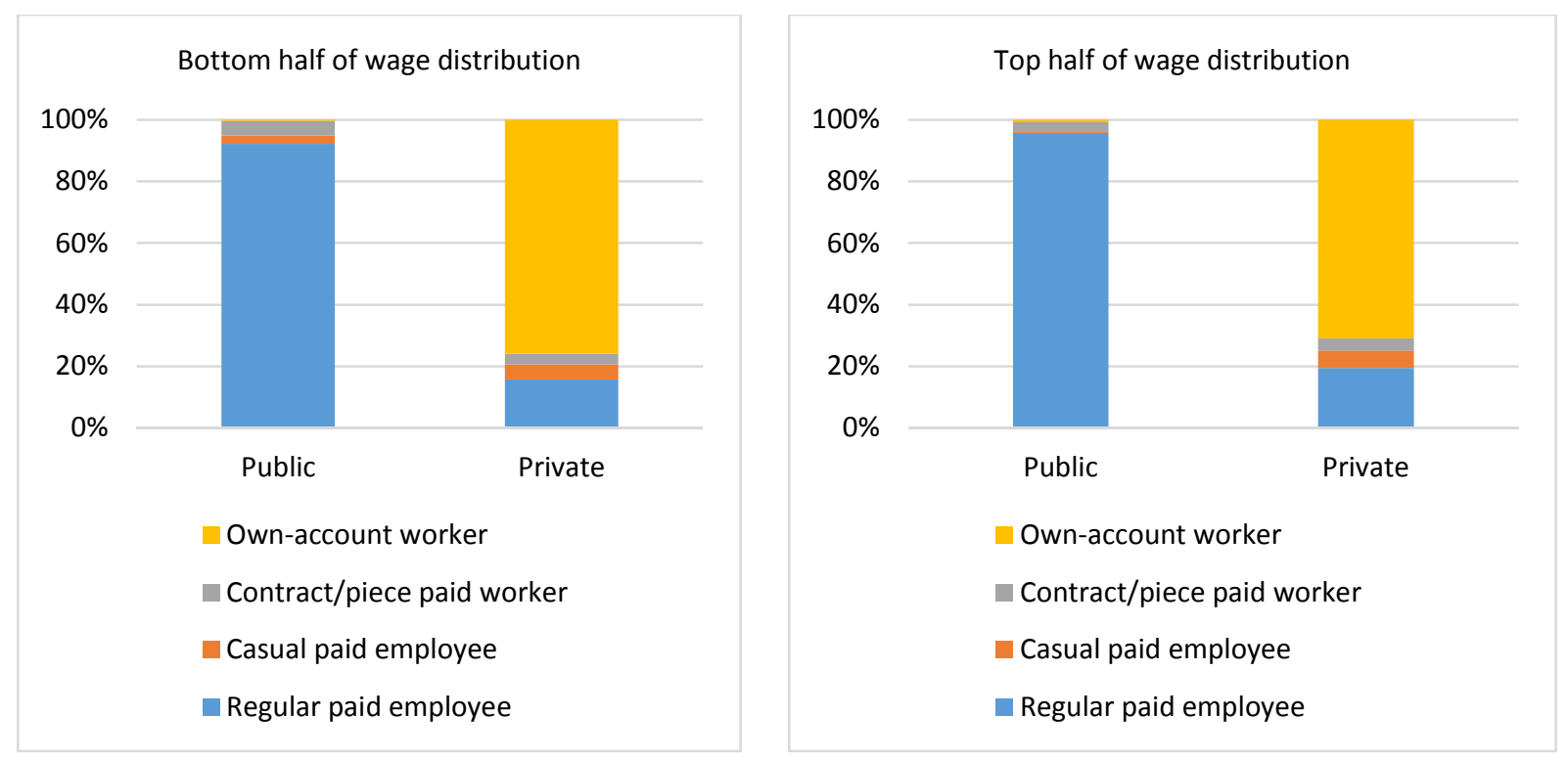

Source: Bhutan Labor Force Survey 2014.

If these differences in the characteristics of public and private sector jobs are ignored, then public sector pay is unambiguously higher across the entire earnings distribution (figure 17). But statistical techniques can be used to control for those differences, and compare pay for workers with similar education and similar jobs. The results shows that a pay gap remains in favor of the public sector across most of the earnings distribution. ${ }^{4}$ The gap is as high as 20 percent across for groups of workers which may represent a sizeable share of the public sector workforce. Only at the top and at the bottom does the public sector pay less than the private sector. This is also a concern, as low pay relative to the private sector can make it difficult for the civil service to retain some of its most qualified and entrepreneurial staff.

Figure 17: The public sector pays more except for workers at the top and the bottom

4 The so-called Oaxaca-Blinder decompositions of the pay gap into job characteristics and returns to those characteristics, as presented in Figure 17, are subject to statistical error and should be interpreted with caution. 


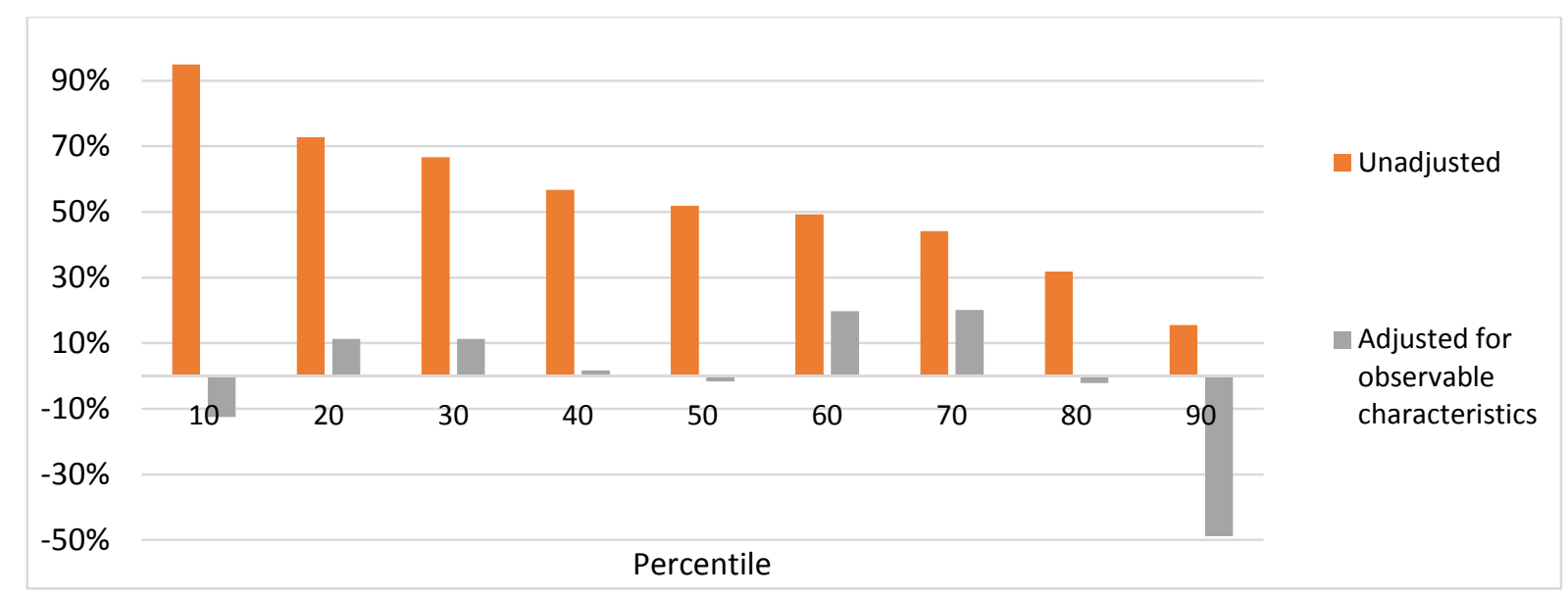

Source: Based on Bhutan Labor Force Survey 2014.

However, delivering on public services does not necessarily require hiring public sector workers. The procurement of works, goods and services is a big ticket item in public spending for private sector growth all over the word. Bhutan is not an exception (box 1). Spending on capital investments (works) dominates its public procurement, while the purchasing of services is only of marginal significance. Outsourcing also helps contain staff numbers in the public sector, hence reducing political pressures on the payroll. Bhutan's experience, however, illustrates the challenges outsourcing poses in a small economy with a still nascent private sector. Contracting with the private sector for road construction and maintenance, where many private companies operate, has yielded generally positive results, in regard to competition and pricing. But outsourcing results in higher costs when the volumes procured are small, and especially when there is little competition among suppliers.

Box 1: Procurement in Bhutan

Distribution of Procurement Spending, 2011-2012

Maintenance of Property

Acquisition of Immovable Property

Training

Expansion of Structures

- Plant \& Equipment

Misc. Office Support Purchase

Professional Services

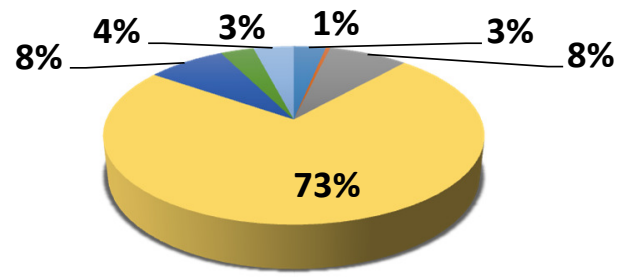

By department and by category 


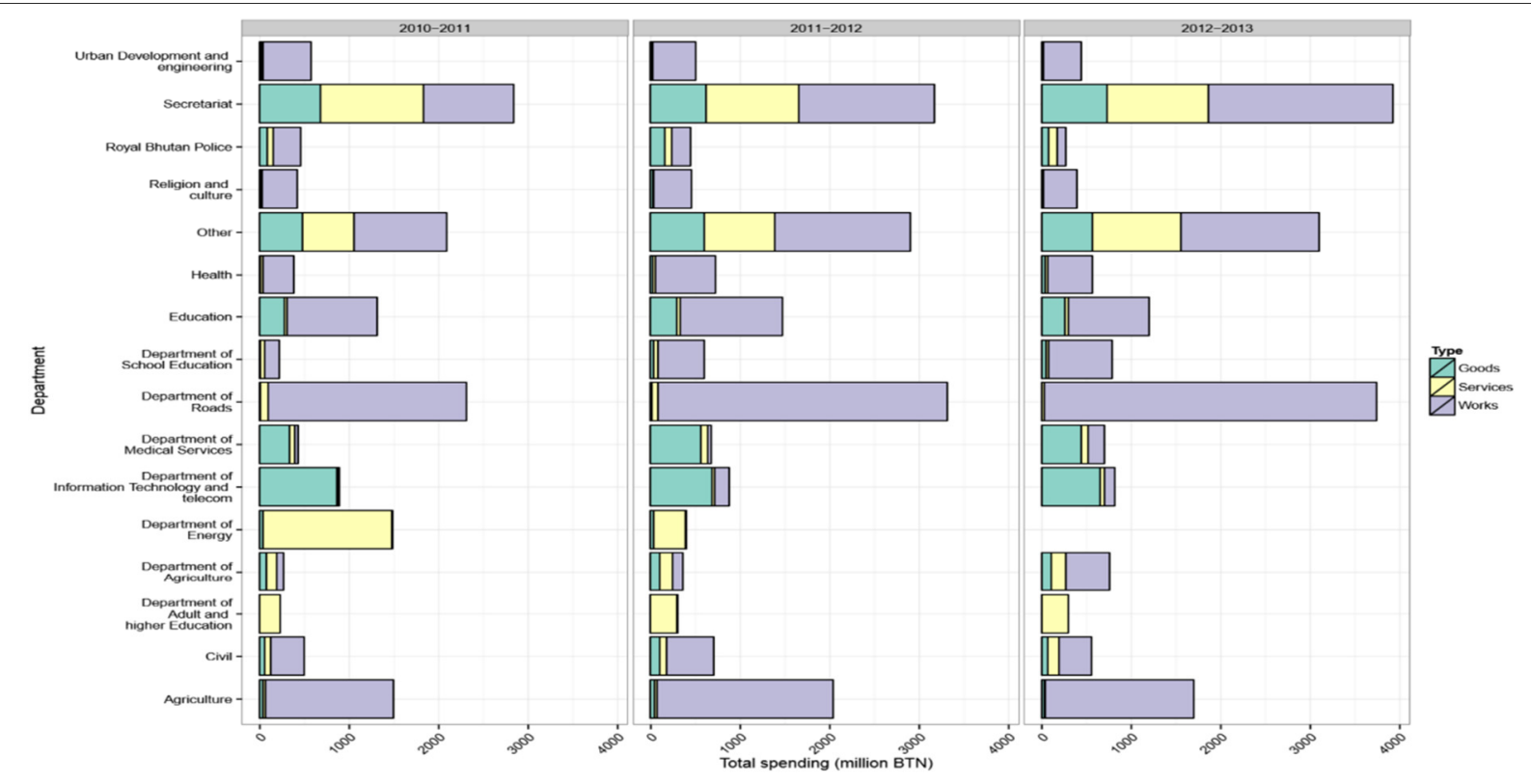

Figure 3: Proportion of spending by category for each department by Goods, by Year

Utilization of Procurement Budgets

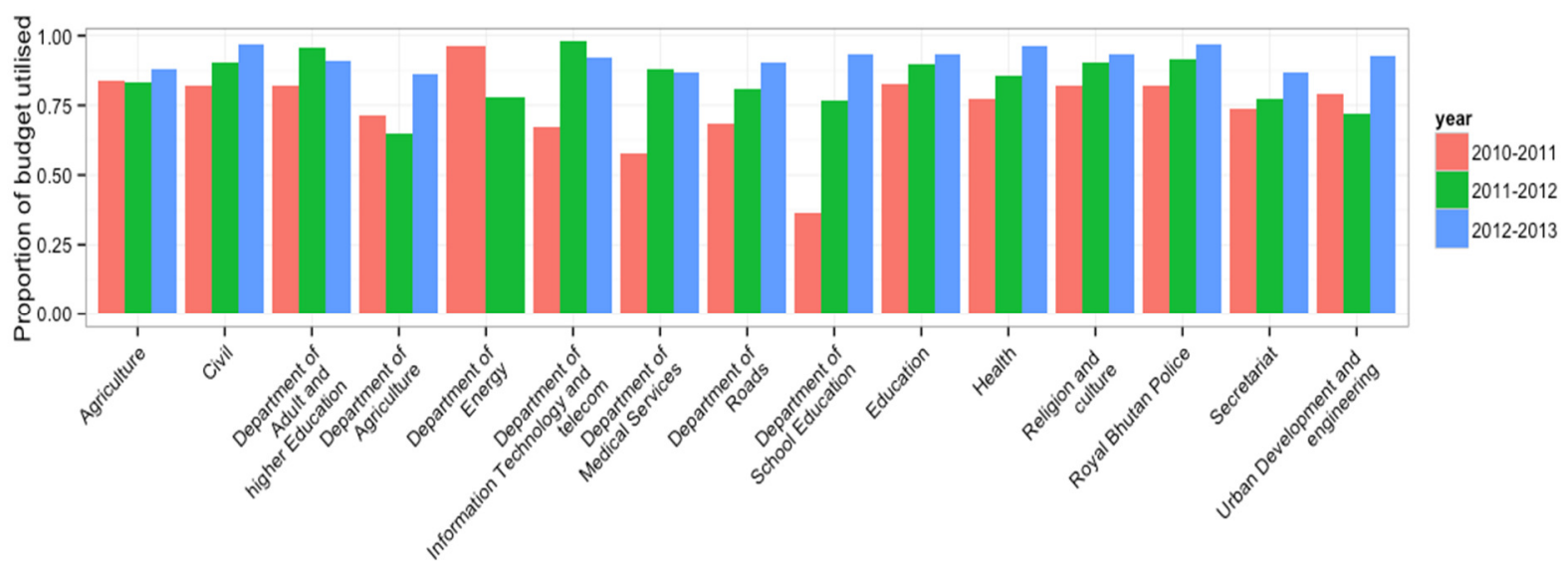

Department

Source: MoF Financial statements.

\section{A paradigm shift and its implementation}

Fast-increasing revenue from hydropower offers a unique chance for Bhutan to continue growing rapidly, to reduce and even eliminate poverty, and to attain its broader development goals. But growing revenue from hydropower also raises three fundamental development challenges.

Because the necessary investments are lumpy and the associated capital inflows and bulky, and because the commissioning of the dams involves a major discontinuity in government revenue, the economy becomes subject to major macroeconomic fluctuations. Fast-increasing hydropower revenue also creates the impression that the economy is on a path to fiscal self-reliance, but this is 
illusory as tax revenue is declining in relative terms, public expenditures in education and health are bound to surge, and the management of capital expenditures can be improved. Last but not least, fast-increasing hydropower revenue makes it difficult to contain the pressures to expand public sector employment and improve public sector pay and benefits, all of which makes queuing for public sector jobs increasingly attractive.

These three major development challenges are connected by one major economic mechanism, and that is public finance. Hydropower revenue is a source of major macroeconomic fluctuations because fiscal policy is pro-cyclical, amplifying the impact of lumpy inflow and discontinuous commissioning on aggregate demand. Hydropower revenue also undermines long-term selfreliance because it makes it attractive to increase public expenditures and ignore the shortcomings of tax revenue. And closely connected to this point, hydropower revenue ends up crowding out private sector employment by making public sector jobs increasingly numerous and attractive.

Addressing these three development challenges therefore requires a fundamental change in Bhutan's approach to public finance. The change can be articulated under the form of a series of inter-connected reforms (table 3). But precisely because they are inter-connected, these reforms cannot be adopted in isolation. What is needed is not a change at the margin but a paradigm shift. And that requires working across several fronts simultaneously.

Recommendation \#1: Bring hydropower investments on-budget

Fiscal policy can play a crucial role in addressing the short-term macroeconomic imbalances generated by hydropower development. The government has so far tried to manage short-term instability - the so-called "rupee crisis" - through microeconomic measures such as import controls and caps on credit expansion. But that amounts to targeting the symptoms rather than the cause. The origin of the recent "rupee crises", and the one that could follow, is macroeconomic, implying that the most appropriate response is to stabilize aggregate domestic demand. In principle this can be done through multiple combinations of counter-cyclical monetary and fiscal policies. However, in an economy with a fixed exchange rate, fiscal policy is more effective than monetary policy. Adopting the most appropriate fiscal policy requires clarity on how expansionary the fiscal stance is. And this is difficult when some of the hydropower development expenses are off-budget. The first recommendation is thus to include in fiscal accounts the capital spending associated hydropower construction, to reflect the true budget surplus or deficit. 
Table 3: Public finance is central to addressing the three development challenges

\begin{tabular}{|c|c|c|}
\hline Development challenge & Paradigm shift & Concrete recommendation \\
\hline \multirow{3}{*}{ Macroeconomic instability } & \multirow{3}{*}{$\begin{array}{l}\text { Countercyclical fiscal } \\
\text { policy }\end{array}$} & $\begin{array}{l}\text { \#1: Bring hydropower investments on- } \\
\text { budget }\end{array}$ \\
\hline & & $\begin{array}{l}\text { \#2: Adopt a medium-term balanced- } \\
\text { budget rule }\end{array}$ \\
\hline & & $\begin{array}{l}\text { \#3: Introduce clear rules to handle } \\
\text { temporary excess revenue }\end{array}$ \\
\hline \multirow{3}{*}{ Lack of fiscal self-reliance } & \multirow{3}{*}{$\begin{array}{l}\text { Medium-term planning and } \\
\text { fiscal frameworks }\end{array}$} & $\begin{array}{l}\text { \#4: Review and limit tax holidays and } \\
\text { exemptions }\end{array}$ \\
\hline & & $\begin{array}{l}\# 5 \text { : Revisit tax instruments and rates for } \\
\text { efficiency and fairness }\end{array}$ \\
\hline & & $\begin{array}{l}\text { \#6: Synchronize planning and budgeting } \\
\text { cycles }\end{array}$ \\
\hline \multirow{3}{*}{ Few private sector jobs } & \multirow{3}{*}{ Demand-side finance } & $\begin{array}{l}\text { \#7: Align public sector compensation } \\
\text { with private sector }\end{array}$ \\
\hline & & $\begin{array}{l}\text { \#8: Rely on "smart" partnerships between } \\
\text { the public and the private sectors }\end{array}$ \\
\hline & & $\begin{array}{l}\text { \#9: Adopt policy frameworks for the } \\
\text { social sectors }\end{array}$ \\
\hline
\end{tabular}

Recommendation \#2: Adopt a medium-term balanced-budget rule

Relying on fiscal policy as a tool to ensure macroeconomic stability requires being able to adjust the fiscal balance up and down depending on the volume of capital inflows entering the country. Given that recurrent expenditures cannot be easily modified in the short term, the government may consider using the public investment program as its main counter-cyclical tool. This would amount to substantially reducing other capital expenditures in periods when major hydro dams are under construction and boosting them when capital inflows subside. Since about two thirds of capital spending is donor-financed, the domestically financed share of capital spending can be used as a buffer, and increasingly so as government moves toward self-reliance. In practice, this requires adopting a credible rule limiting recurrent expenditures while allowing flexibility on capital expenditures and using smoothed-out revenue instead of annual revenue for budgeting purposes.

Bhutan's Constitution requires that domestic revenues should cover at least current expenditures. In addition, a stated goal of the five-year plan is to cover 85 percent of total spending by domestic revenues by 2018. These rules provide a transparent disciplining device for public spending. But looking forward, once domestic revenues start increasing significantly, the recurrent spending rule 
will not be binding any longer, and the temptation to increase recurrent spending will be difficult to resist.

An alternative rule is to enforce fiscal discipline over a longer time horizon, in the spirit of Chile's medium-term balanced budget rule. That means spending less in times of abnormally high government revenue, and more in times of relatively low revenue. These gaps should be seen not in relation to a constant level of public expenditures, but rather in relation of a level that will be trending upward as the coverage and quality of public services increases. At a very minimum, recurrent spending can be capped by its average as a share of GDP over the last few years. More sophisticated approaches involve the forecasting of a revenue trend, and the introduction of business cycle considerations. Whichever mechanism is chose to smooth out revenue, it is important to isolate it from political interference.

Recommendation \#3: Introduce clear rules to handle temporary excess revenue

A successful medium-term balanced budget rule implies that there will be periods with budget surpluses, especially during the decade when hydropower revenue surges as a result of the ongoing and planned investments. Indeed, if resources are not accumulated during the decade of rapid growth in hydropower revenue, Bhutan will be confronted with either cutting public expenditures or raising tax revenue substantially further down the road. But the resulting surpluses need to be protected from political pressure for profligacy, and be invested wisely. For that, there has to be a separate account to park those excess resources, clear rules on their authorized uses, and a strong governance mechanism to prevent that they be used - directly or indirectly - to finance recurrent of capital expenditures. For example, the stabilizing objective of the medium-term balanced budget rule would be undermined if resources sitting in this account were "lent" to the government to finance a higher level of public expenditures. Defining the asset classes in which resources from this special account can be invested would go a long way towards addressing this risk. But good governance would also require setting caps for investments in assets of different classes, benchmarking the expected returns in each case, appointing a board with the expertise and authority to make the relevant decisions, and reporting to the Parliament on investments and returns on an annual basis. The investment funds created by resource-rich countries, as well as many public pension funds, provide good guidance on how to do all this.

Recommendation \#4: Review and limit tax holidays and exemptions

If profligate spending puts fiscal self-reliance at risk, the most immediate challenge to self-reliance comes from low and declining tax revenue. A considerable fraction of the loss in revenue comes from overly generous tax holidays and exemptions. There is no question that a more favorable tax regime can attract additional investment, but whether they do so is an empirical question. Special regimes should be considered as a public investment, with an expected, measurable, socioeconomic return. They should be established with parsimony and justified by an expected 
measurable impact. In the absence of any evidence of such an impact, they should be discontinued. But this approach should not be applied only to future exemptions and tax holidays. A thorough revision of the exemptions and incentives granted so far is also warranted, with a shift back to the general regime as the default option, unless this violates legal obligations of the government.

Recommendation \#5: Revisit tax instruments and rates for efficiency and fairness

Bhutan's tax instruments and tax rates are not out of line with those of other developing countries. If anything, the share of households paying taxes is considerably higher than in other countries at a similar development level. This provides a solid foundation to generate tax revenue without over-burdening any particular population group. However, Bhutan's tax instruments and tax rates also create disincentives and generate inequities. Investment decisions by firms are guided by returns, and these are supposed to indicate where the payoffs to resources are higher. But the "signal" in the returns is distorted by tax holidays and exemptions. Similarly, work decisions by households are guided by the earnings they can make, guiding them towards the most productive activities. But tax instruments and thresholds blur these signal too, for instance if they encourage less productive activities that remain out of the scope of Personal Income Tax or Business Income Tax. In the drive towards fiscal self-reliance, it would be advisable to reassess the current set of tax instruments and rates with a focus on neutrality and equity. In particular, the rates and thresholds of Business Income Tax and Personal Income Tax should be revised so as to ensure an implicit tax rate that is mildly progressive and does not penalize formal employment.

Recommendation \#6: Synchronize planning and budgeting cycles

Ensuring fiscal self-reliance will be difficult if there are sizeable gaps between planned and actual public spending. Yet this is currently the case, especially in relation to capital expenditures. These gaps are not due to the lack of medium-term expenditure frameworks. But the link between the plan and these medium-term expenditure frameworks, as well as between them and annual budgets, is not as robust as it should. One of the weaknesses is the misalignment of the budget cycle and the political cycle. Under the current setting, a new government inherits the budget prepared by the previous one, which is bound to lead to adjustments. Another weak link is the insufficient costing of the budget implications of sectoral strategies, such as the Education Blueprint. Last but not least, capital expenditures could be more strategic and anchored into sector medium-term planning and budgeting, with recurrent spending implications budgeted in.

As Bhutan transitions from grant finance to self-reliance for its capital expenditures, key sectors should develop medium-term expenditure frameworks, covering both capital and recurrent expenditures, within the multi-year fiscal envelopes provided by the Ministry of Finance. The smoothed-out revenue forecast should be a key input in this exercise, to strengthen the consistency between the overall resource envelope available and expenditures at the sector level. 
Recommendation \#7: Align public sector compensation with private sector

Salaries and benefits are one of the biggest items in total public spending. And the share of salaries and benefits in public spending will increase further as basic infrastructure investments (e.g. building schools, or rural roads) will be completed and expenditure will be gradually reoriented towards service delivery, in the social sectors in particular. In addition to their impact on the budget, salaries and benefits in government have other important implications for economic efficiency. If they are above the alternatives, they generate incentives to queue for public sector jobs, promoting unemployment and depriving the private sector from young and talented workers. Changes in civil service salaries and benefits also drive change in wages in the rest of the economy, first in the public corporate sector, and then in private sector, real estate rentals, and so on. Through this mechanism they make the cost of labor more expensive for the private sector, undermining its competitiveness.

The recommendation in this case is to gradually align net compensation in the public sector with private sector alternatives and move to adjusting the public wage bill annually rather than every five years. Admittedly, despite many public sector jobs carrying an earnings premium, the government will almost certainly confront political pressures to increase civil servant salaries and improve their benefits. This is why the work of the Pay Commission needs to be underpinned by strong empirical analyses to keep those pressures at bay and contain the ballooning of public expenditures. In practice, this requires assessing the true employment alternatives of public sector workers, including not just the best formal sector employers in the country but also the types of jobs - formal and informal - done by people with similar educational attainment and work experience. Household surveys and labor force surveys often provide a good foundation to conduct these comparisons in a rigorous manner. The ratio of applicants per public sector vacancy is also a clear indication of the relative attractiveness - at times excessive - of public sector jobs.

Recommendation \#8: Rely on "smart partnerships" between the public and the private sector

The development of a private sector in Bhutan is critically dependent on how the government will manage over time the revenue from hydropower generation. As revenues flow in, the prices of non-tradable goods and services (such as land, real estate, and labor) increase relatively to the prices of tradable goods (such as food or software), constraining private sector competitiveness in external markets. Policy reforms aimed at developing a more supportive investment climate can partially offset this disadvantage. But they may turn out to be insufficient in light of the magnitude of the inflows Bhutan will receive. A pro-active public finance approach to deliberately support the emergence of a private sector is needed as well. That means ensuring that the public sector actually crowds in private sector jobs.

Procurement in infrastructure building and maintenance has delivered very positive results in this respect. Many private sector companies work as contractors for government, and because they 
need to play by the rules to be eligible, they provide jobs complying with labor regulations. Outsourcing a larger proportion of non-core activities, such as maintenance or IT services, could also go a long way towards providing new opportunities for the private sector at the same time that it would serve to increase the efficiency of spending. The experience in these other areas has not been encouraging so far, but to some extent this reflects problems with the design of public procurement, rather than with the approach.

While outsourcing at the margin can lead to failure, the government could be proactive in generating the scale necessary to brings costs down, and in designing tenders in a way that addresses imperfect competition. This can be accomplished by consolidating purchases across agencies. An area in which the government could reach the scale needed to elicit a competitive private sector response is in the framework agreements for IT services. A greater scale can be attained by relying on multi-year framework agreements instead of individual transactions to procure goods and services. Importantly, the benchmarking of eligible bids relative to competitive prices would provide a safeguard to avoid proceeding with potentially costly tenders. Border prices - including import duties and taxes - can be used as the price ceiling whenever possible.

Recent years have also seen the emergence of a wide range of PPP structures, with varying degrees of risk taken by the private and public sectors. "Smart partnerships" between the private and the public sectors can take a variety of forms, ranging for example from concessions to "Public Service Contracts" (PSCs). The latter define rights and obligations between a public entity (e.g. government or municipality) and a public or private provider and, in particular, the formula for the service payments to be provided to the provider in return for the delivery of services. PSCs should also include provision for capital investments. Arrangements of this sort are being increasingly used with success in the public transport sector in Eastern Europe. Bhutan could usefully explore entering into such a PSCs for public urban transports, or with other public organizations which receive public subsidies.

Recommendation \#9: Adopt policy frameworks for the social sectors

Education and health will be among the fastest growing sectors in Bhutan, but it does not follow that the provision of these services needs to be entirely - or even predominantly - in the hands of the government. These are areas in which fruitful partnerships between the public and the private sector can reconcile universalism with efficiency. In addition to the obvious outsourcing of ancillary services, such as school meals and hospital cleaning, there is scope to have vibrant private education institutions and health care providers. But these need to operate under the umbrella of clearly defined policy frameworks ensuring equity and cost containment. 
Box 2 - Policy frameworks are needed for private participation in education and health

In the absence of strategic planning, the expansion of social services needed by Bhutan is bound to happen through public supply, resulting in the massive hiring of teachers, doctors, nurses and other personnel as civil servants. If so, the share of public sector employment in total employment will increase substantially, and political influence to improve salaries and benefits will become even more pressing. However, the expansion of education and health services can also be accomplished through the involvement of the private sector and civil society organizations, with financial resources and accreditation provided by the government.

Against the background of Bhutan's model of universal service provider, options can be found for the public and private sectors to engage into mutually beneficial partnership to provide public services. These opportunities might be found in contracting out non-core services across public sector functions and in gradually and carefully shifting systems of delivery to the demand side.

Education - Private sector participation has proved crucial in improving the quality and market relevance of tertiary and technical education in Bhutan. But the number of places available in the colleges and the technical training institutes is very limited, as is the number of scholarships attached with the Royal University of Bhutan. This leaves few options for talented youth who want to pursue technical and tertiary education. Creating healthy competition, rewarding innovative approaches and drive for results can help address this constraint. For instance, vouchers for vocational education and training and for tertiary education can allow deserving students to choose among certified training centers and schools, both public and private. This would ensure competition among the institutes for results and responsiveness to the market demand. Students would also enjoy more freedom in choosing their fields of interest. Bhutan may also explore the possibility of allowing internationally recognized institutes to open local antennas, also allowing them to admit foreign students to strengthen their sustainability. This would benefit Bhutan in several ways: it would support the establishment of in-country world class education facility, it would foster competition among education providers, it would reduce expenditures, and it would support the creation of highly skilled jobs.

Health - Introducing private provision is more demanding in the case of health services, as crude provider payments (such as fee for service) can increase costs substantially without necessarily improving health outcomes. This risk provides a strong justification to start thinking early on about the design of provider payments and information systems for the health sector. A pro-active approach of this sort could help build demand for skilled private sector jobs in sectors with considerable growth potential. Indeed, before embarking on a path of promoting the delivery of private health services, it is important to learn the lessons of other developing countries, and to avoid their mistakes. In many cases, a fee-for-service approach or cost-based reimbursement for health expenditures incentivized unnecessary diagnosis and treatment. To prevent the associated cost escalation, many health systems are implementing alternative payment systems, with more reliance on prospective and bundling methods such as capitation for primary health care or case-based payment for hospitals. Under this system, a fixed amount is paid in advance to provide a defined set of services for a fixed period of time. This methodology has cost-control incentives and prevents unnecessary care. But the adoption of these alternative provider payment systems requires the development of information systems that link personal identification information with medical diagnoses, medical procedures, and the associated financial costs. Affordable private sector participation in the health sector would again boost the creation of skilled jobs. In particular, given the scarcity of doctors in Bhutan, a strategy focused on the development of private diagnostic services - laboratory, radiology and the like - would be highly appropriate, as it would require mainly nurses and technicians who can be trained locally. In parallel, twinning under public-private partnerships with overseas universities and research centers can help build the necessary cadre of medical specialists. 
Outsourcing is more challenging in the social sectors than in infrastructure, IT services, or maintenance. Private providers may introduce more differentiation of outcomes than is socially acceptable in a country with a strong preference for equality. Importantly, in the absence of robust provider payment systems, outsourcing may end up being more expensive than public sector delivery. For instance, in many developing countries the introduction of private agents in the health sector is first done under a fee-for-service regime which results in an explosion of unwarranted analyses and medical interventions. Fostering public-private partnerships in the social sectors thus requires a prior effort to develop the appropriate policy frameworks and information systems in each sector (box 2). 